\title{
Nonlinear Programming Techniques for Operative Planning in Large Drinking Water Networks
}

\author{
Jens Burgschweiger ${ }^{1}$, Bernd Gnädig ${ }^{2}$ and Marc C. Steinbach ${ }^{3, *}$ \\ ${ }^{I}$ Berliner Wasserbetriebe, Abt. NA-G/W, 10864 Berlin, Germany \\ ${ }^{2}$ Düsseldorf, Germany \\ ${ }^{3}$ Leibniz Universität Hannover, IfAM, Welfengarten 1, 30167 Hannover, Germany
}

\begin{abstract}
Mathematical decision support for operative planning in water supply systems is highly desirable; it leads, however, to very difficult optimization problems. We propose a nonlinear programming approach that yields practically satisfactory operating schedules in acceptable computing time even for large networks. Based on a carefully designed model supporting gradient-based optimization algorithms, this approach employs a special initialization strategy for convergence acceleration, special minimum up and down time constraints together with pump aggregation to handle switching decisions, and several network reduction techniques for further speed-up. Results for selected application scenarios at Berliner Wasserbetriebe demonstrate the success of the approach.
\end{abstract}

Keywords: Water supply, large-scale nonlinear programming, convergence acceleration, discrete decisions, network reduction.

\section{INTRODUCTION}

Stringent requirements on cost effectiveness and environmental compatibility generate an increased demand for model-based decision support tools for designing and operating municipal water supply systems. This paper deals with the minimum cost operation of drinking water networks. Operative planning in water networks is difficult: a sound mathematical model leads to nonlinear mixedinteger optimization, which is currently impractical for large water supply networks as in Berlin. Because of the enormous complexity of the task, early mathematical approaches typically rely on substantially simplified network hydraulics (by dropping all nonlinearities or addressing the static case, for instance) [1-8], which is often unacceptable in practice. Other authors employ discrete dynamic programming [9-14], which is mathematically sound but only applicable to small networks unless specific properties can be exploited to increase efficiency. Optimization methods based on nonlinear models (mostly for the pumps only) are reported in [15-19]. These approaches employ computationally expensive meta-heuristics or suffer from inefficient coupling of gradient-based optimization with non-smooth simulation by existing network hydraulics software, such as EPANET [20]. Other topics in water management include network design [21-24], online control [25, 26], state estimation [27], and contamination detection [28]. More loosely related recent work addresses modeling and optimization for networks of irrigation and sewage canals or for gas networks, see, e.g., [29-35]. Previous efforts toward minimum cost operation at Berliner Wasserbetriebe include:

*Address correspondence to this author at the Leibniz Universität Hannover, IfAM, Welfengarten 1, 30167 Hannover, Germany; E-mail: steinbach@ifam.uni-hannover.de; http://www.ifam.uni-hannover.de/steinbach

2000 Mathematics Subject Classification. 65K10, 90C06, 90C11, 90C30, 90C $35,90 \mathrm{C} 90$.
- experiments with various optimization models and methods [36, 37],

- a first nonlinear programming (NLP) model developed under GAMS [38],

- numerical results for a substantially reduced network graph using (under GAMS) the SQP codes CONOPT, SNOPT, and the augmented Lagrangian code MINOS.

The main goal of the joint work reported here is the development of a decision support tool suitable for routine application, to be implemented as an optimization module within the new operational control system of Berliner Wasserbetriebe. The approach is restricted to the framework sketched above: a pure NLP model (no integer variables), the GAMS modeling environment, and the listed NLP solvers. Criteria for applicability are speed (response time), reliability, and practicability. Our mathematical developments toward these goals are based on two internal studies [39, 40] and can be coarsely categorized into modeling techniques (reported in [41]) and nonlinear programming techniques (reported here). Basic modeling techniques include, in particular, a globally smooth and asymptotically correct approximation of the hydraulic pressure loss in pipes, and suitably aggregated models for collections of pumps that operate in parallel. The NLP techniques include, among others, a sequential linear programming type initialization procedure for the nonlinear iteration, special constraints that ensure minimum up and down times in pump operation, and various network reduction techniques. Together with pump aggregation, the up and down time constraints permit the handling of discrete decisions (pump switching) without introducing binary variables. Following the NLP-based network-wide optimization, nonlinear mixed-integer models are solved locally at each waterworks. 
Table 1. Notation

\begin{tabular}{|c|c|c|c|}
\hline Symbol & Explanation & Value & Unit \\
\hline $\mathrm{Q}$ & Volumetric flow rate in arcs & & $\mathrm{m}^{3} / \mathrm{s}$ \\
\hline $\mathrm{D}$ & Demand flow rate at junctions & & $\mathrm{m}^{3} / \mathrm{s}$ \\
\hline $\mathrm{H}$ & Pressure potential at nodes (head) & & $\mathrm{m}$ \\
\hline$\Delta \mathrm{H}$ & Pressure increase at pumps, decrease at valves & & $\mathrm{m}$ \\
\hline $\mathrm{L}$ & Pipe length & & $\mathrm{m}$ \\
\hline $\mathrm{d}$ & Pipe diameter (bore) & & $\mathrm{m}$ \\
\hline $\mathrm{k}$ & Pipe roughness & & $\mathrm{m}$ \\
\hline $\mathrm{A}$ & Pipe cross-sectional area & & $\mathrm{m}^{2}$ \\
\hline$\lambda$ & Pipe friction coefficient & & - \\
\hline $\mathrm{r}$ & Pipe hydraulic loss coefficient & & $\mathrm{s}^{2} / \mathrm{m}^{5}$ \\
\hline$\rho$ & Water density & 1000 & $\mathrm{~kg} / \mathrm{m}^{3}$ \\
\hline $\mathrm{g}$ & Gravity constant & 9.81 & $\mathrm{~m} / \mathrm{s}^{2}$ \\
\hline
\end{tabular}

We start by summarizing the component models of all the network elements in Section 1, followed by the overall NLP model. In Section 2, the smoothing and SLP initialization are discussed along with further convergence enhancement techniques. Section 3 is devoted to combinatorial issues, particularly the prevention of undesired pump switching. Several network reduction strategies are then developed in Section 4 with special emphasis on suitable smoothing of the hydraulic friction loss. Finally, Section 5 presents selected application scenarios at Berliner Wasserbetriebe in order to demonstrate the success of our approach.

\section{OPTIMIZATION MODEL}

We will first summarize the nonlinear programming model developed in [41] in order to keep the paper selfcontained. This model covers the physical and technical network behavior. Later on we will add further constraints and develop graph reduction techniques to achieve a desired solution behavior and to enable efficient treatment by the selected standard NLP solvers. The basic notation used in our model is given in Table $\mathbf{1}$.

\subsection{Network Topology}

The network model is based on a directed graph $\mathrm{G}=(\mathcal{N}$, $\mathcal{A}$ ) whose node set represents junctions, reservoirs, and tanks, and whose arc set represents pipes, pumps, and gate valves,

$$
\begin{aligned}
& \mathcal{N}=\mathcal{N}_{\mathrm{jc}} \cup \mathcal{N}_{\mathrm{rs}} \cup \mathcal{N}_{\mathrm{tk}}, \\
& \mathcal{A}=\mathcal{A}_{\mathrm{pi}} \cup \mathcal{A}_{\mathrm{pu}} \cup \mathcal{A}_{\mathrm{vl}} .
\end{aligned}
$$

The set of pumps consists of raw water pumps and pure water pumps, $\mathcal{A}_{\mathrm{pu}}=\mathcal{A}_{\mathrm{pr}} \cup \mathcal{A}_{\mathrm{pp}}$. We denote arcs as $a \in \mathcal{A}$ or, with tail and head $\mathrm{i}, \mathrm{j} \in \mathcal{N}$, as $\mathrm{ij} \in \mathcal{A}$. A flow from $\mathrm{i}$ to $\mathrm{j}$ is positive, from $\mathrm{j}$ to $\mathrm{i}$ negative.

Fig. (1) illustrates the main network of Berliner Wasserbetriebe, with 1481 nodes and 1935 arcs. Earlier investigations were based on a small test configuration with 144 nodes and 192 arcs; cf. [41].

\subsection{Optimization Horizon and Dynamic Variables}

We consider a planning period of length $\mathrm{T}$ in discrete time, $\mathrm{t}=1,2, \ldots, \mathrm{T}$, with initial conditions at $\mathrm{t}=0$. The subinterval $(t-1, t)$ will be referred to as period $t$ and has the physical length $\Delta \mathrm{t}$. At Berliner Wasserbetriebe, the planning period represents the following day in 24 hourly intervals.

We measure the pressure by the head $\mathrm{H}$ : the sum of the geodetic elevation and of the elevation gain corresponding to the hydraulic pressure. Pressure variables $\mathrm{H}_{\mathrm{it}}$ are associated with every node $\mathrm{j} \in \mathcal{N}$ and time period t. Volumetric flow rates $\mathrm{Q}_{a t}$ are associated with every arc $a \in \mathcal{A}$. Control variables are the pressure increase across pumps and decrease across valves, $\Delta \mathrm{H}_{a t}, a \in \mathcal{A}_{\mathrm{pu}} \cup \mathcal{A}_{\mathrm{vl}}$. All variables have simple bounds.

\subsection{Network Dynamics and Model Constraints}

The network hydraulics include over-all flow balances and pressure relations, with one equation per network element:

$$
\begin{array}{llr}
0=c_{\mathrm{jt}}^{\text {flow }}:=\sum_{\mathrm{i} \mathrm{ij} \in \mathcal{A}} \mathrm{Q}_{\mathrm{ijt}}-\sum_{\mathrm{k} . \mathrm{jk} \in \mathcal{A}} \mathrm{Q}_{\mathrm{jkt}}-\mathrm{D}_{\mathrm{jt}}, & \mathrm{j} \in \mathcal{N}_{\mathrm{jc}}, \\
0=\mathrm{c}_{\mathrm{jt}}^{\text {flow }}:=\sum_{\mathrm{i} \mathrm{j} \mathrm{j} \in \mathcal{A}} \mathrm{Q}_{\mathrm{ijt}}-\sum_{\mathrm{k} \mathrm{j} \mathrm{j} \in \mathcal{A}} \mathrm{Q}_{\mathrm{jkt}}-\mathrm{E}_{\mathrm{jt}}\left(\mathrm{H}_{\mathrm{j}, \mathrm{t}-1}, \mathrm{H}_{\mathrm{jt}}\right), & \mathrm{j} \in \mathcal{N}_{\mathrm{tk}}, \\
0=\mathrm{c}_{\mathrm{jt}}^{\text {head }}:=\mathrm{H}_{\mathrm{jt}}-\overline{\mathrm{H}}_{\mathrm{j}}, & \mathrm{j} \in \mathcal{N}_{\mathrm{rs}}, \\
0=\mathrm{c}_{a \mathrm{t}}^{\text {loss }}:=\mathrm{H}_{\mathrm{jt}}-\mathrm{H}_{\mathrm{it}}+\Delta \mathrm{H}_{a}\left(\mathrm{Q}_{a \mathrm{t}}\right), & a=\mathrm{ij} \in \mathcal{A}_{\mathrm{pi}}, \\
0=\mathrm{c}_{a \mathrm{t}}^{\text {diff }}:=\mathrm{H}_{\mathrm{jt}}-\mathrm{H}_{\mathrm{it}}-\Delta \mathrm{H}_{a t}, & a=\mathrm{ij} \in \mathcal{A}_{\mathrm{pu}}, \\
0=\mathrm{c}_{a \mathrm{t}}^{\text {diff }}:=\mathrm{H}_{\mathrm{jt}}-\mathrm{H}_{\mathrm{it}}+\Delta \mathrm{H}_{a t}, & a=\mathrm{ij} \in \mathcal{A}_{\mathrm{vl}}, \\
0 \leq \mathrm{c}_{a \mathrm{t}}^{\text {sign }}:=\Delta \mathrm{H}_{a t} \mathrm{Q}_{a \mathrm{t}}, & a=\mathrm{ij} \in \mathcal{A}_{\mathrm{vl}},
\end{array}
$$

Externally given data include the predicted junction demands $D_{j t}$, constant reservoir heads $\overline{\mathrm{H}}_{\mathrm{j}}$, tank inflow 


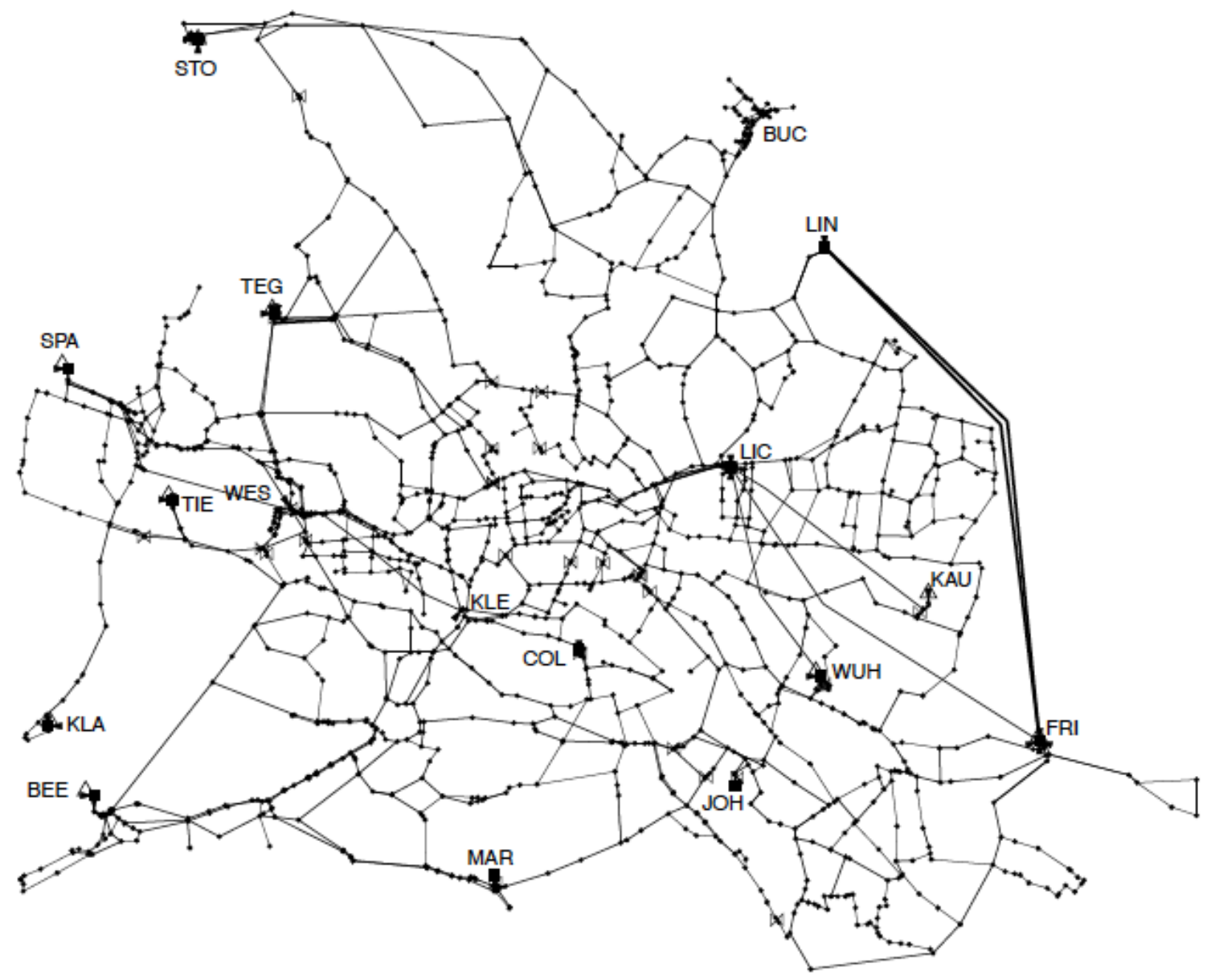

Fig. (1). Main distribution network of Berliner Wasserbetriebe.

characteristics $\mathrm{E}_{\mathrm{jt}}\left(\mathrm{H}_{\mathrm{j}, \mathrm{t}-1}, \mathrm{H}_{\mathrm{jt}}\right)$, and pipe pressure loss characteristics $\Delta \mathrm{H}_{a}\left(\mathrm{Q}_{a t}\right)$. The sign condition (5) ensures consistency of the valve pressure decrease with the unknown direction of flow.

The hydraulic pressure loss in pipes is usually expressed in terms of a loss coefficient $r_{a}\left(Q_{a t}\right)$ depending on the pipe length and diameter,

$\Delta \mathrm{H}_{a}\left(\mathrm{Q}_{a \mathrm{t}}\right)=\mathrm{r}_{a}\left(\mathrm{Q}_{a \mathrm{t}}\right) \mathrm{Q}_{a \mathrm{t}}\left|\mathrm{Q}_{a \mathrm{t}}\right|, \quad \mathrm{r}_{a}\left(\mathrm{Q}_{a \mathrm{t}}\right)=\frac{8 \mathrm{~L}_{a}}{\pi^{2} \mathrm{gd}_{a}^{5}} \lambda_{a}\left(\mathrm{Q}_{a \mathrm{t}}\right)$,

where the friction coefficient $\lambda_{a}\left(\mathrm{Q}_{a t}\right)$ depends on the flow rate and the pipe roughness $\mathrm{k}_{a}$. A highly accurate model for $\lambda_{a}$ is based on the laws of Hagen-Poiseuille (laminar flow) and Prandtl-Colebrook (turbulent flow); we call this the HP$P C$ model. A much simpler and flow-independent formula is the law of Prandtl-Kármán for rough pipes ( $\mathrm{PKr}$ model),

$\lambda_{a}^{\mathrm{PKr}}=\left(2 \log \frac{\mathrm{k}_{a} / \mathrm{d}_{a}}{3.71}\right)^{-2}, \quad \mathrm{r}_{a}^{\mathrm{PKr}}=\frac{8 \mathrm{~L}_{a}}{\pi^{2} \mathrm{gd}_{a}^{5}} \lambda_{a}^{\mathrm{PKr}}$,

which provides a valid approximation for highly turbulent flow, that is, large $\mathrm{Q}_{a \mathrm{t}}$. An important element of our approach is a globally smooth, asymptotically correct approximation $\Delta \mathrm{H}_{a}^{\mathrm{PKr}}$ that shares the leading coefficient with the $\mathrm{r}_{a}^{\mathrm{PKr}}$ model. We call it the smoothed PKr model (PKrs model); for more details see [41] and Section 2. 1.
Nontrivial inequalities include bounds on: the flow gradients at the raw water pumps, the daily discharge of the waterworks outlets, $a \in \mathrm{A}_{\mathrm{po}}$, and the total power consumption of raw water and pure water pumps $a \in \mathcal{A}_{\mathrm{pr}}(w) \cup \mathcal{A}_{\mathrm{pp}}(w)$ at each waterworks or pumping station, $w \in \mathcal{W}$ :

$\mathrm{c}_{a t}^{\mathrm{grad}}:=\mathrm{Q}_{a t}-\mathrm{Q}_{a, \mathrm{t}-1} \in\left[\Delta \mathrm{Q}_{a \mathrm{t}}^{-}, \Delta \mathrm{Q}_{a \mathrm{t}}^{+}\right], \quad a \in \mathcal{A}_{\mathrm{pr}}$,

$\mathrm{c}_{a}^{\mathrm{day}}:=\Delta \mathrm{t} \sum_{\mathrm{t}=1}^{\mathrm{T}} \mathrm{Q}_{a \mathrm{t}} \in\left[\Sigma \mathrm{Q}_{a \mathrm{t}}^{-}, \Sigma \mathrm{Q}_{a \mathrm{t}}^{+}\right], \quad a \in \mathcal{A}_{\mathrm{po}}$,

$\mathrm{c}_{a t}^{\mathrm{pow}}:=\sum_{a \in \mathcal{A}_{\mathrm{pr}}(w)} w_{a \mathrm{t}}^{\mathrm{raw}} \mathrm{Q}_{a \mathrm{t}}+\sum_{a \in \mathcal{A}_{\mathrm{pp}}(w)} \frac{\rho g \Delta \mathcal{H}_{a \mathrm{t}} \mathrm{Q}_{a \mathrm{t}}}{\eta_{a}\left(\mathrm{Q}_{a \mathrm{t}}\right)} \leq \mathrm{p}_{w,}^{+} \quad w \in \mathcal{W}$.

Table 2. Notation for the Cost Function

\begin{tabular}{|c|c|c|}
\hline Symbol & Explanation & Unit \\
\hline K & Total daily operating cost & $€$ \\
\hline $\mathrm{k}_{a \mathrm{t}}^{\mathrm{el}}$ & Price for electric energy at pump a during period $t$ & $€ / J$ \\
\hline $\mathrm{k}_{a}^{\mathrm{raw}}$ & $\begin{array}{l}\text { Specific price for raw water and treatment materials } \\
\text { at pump } a\end{array}$ & $€ / \mathrm{m}^{3}$ \\
\hline$w_{a \mathrm{t}}^{\mathrm{raw}}$ & $\begin{array}{l}\text { Specific work for raw water pumping and treatment } \\
\text { at pump } a\end{array}$ & $\mathrm{~J} / \mathrm{m}^{3}$ \\
\hline
\end{tabular}




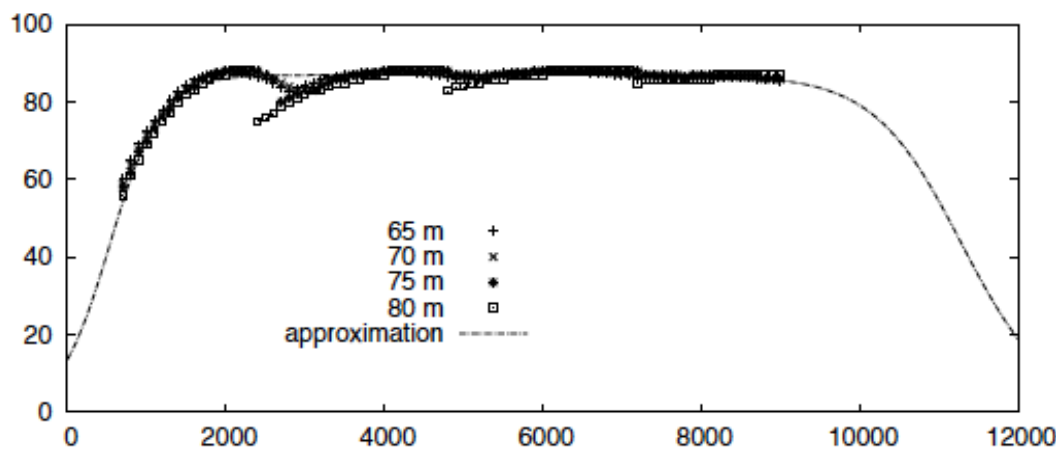

Fig. (2). Efficiency of aggregated pure water pumps under optimal configuration.

Here $\eta_{a}\left(\mathrm{Q}_{a t}\right)$ is a smooth approximation of the efficiency of pure water pumps (actually small groups of them), see $[41, \S 2.8]$ and Fig. (2).

Relevant initial values are $\mathrm{H}_{\mathrm{j} 0}, \mathrm{j} \in \mathcal{N}_{\mathrm{tk}}$, and $\mathrm{Q}_{a 0}, a \in \mathcal{A}_{\mathrm{pr}}$, entering into constraints (2) and (8), respectively. The remaining initial pump flows $\mathrm{Q}_{a 0}, a \in \mathcal{A}_{\mathrm{pp}}$, will be required for the minimum up and down time constraints of Section 3.2. Undesired finite horizon effects are prevented by tightened lower bounds $\mathrm{H}_{\mathrm{jT}}^{-} \mathrm{j} \in \mathcal{N}_{\mathrm{tk}}$ ("terminal constranints").

\subsection{Objective Function}

The overall goal is to minimize the variable operating costs,

$\mathrm{K}=\Delta \mathrm{t} \sum_{\mathrm{t}=1}^{\mathrm{T}}\left(\mathrm{K}_{\mathrm{t}}^{\mathrm{raw}}+\mathrm{K}_{\mathrm{t}}^{\text {pure }}\right)$.

If we use the cost coefficients in Table 2 and let $\mathrm{k}_{a}^{\mathrm{raw}}=\mathrm{w}_{a \mathrm{t}}^{\mathrm{raw}} \mathrm{k}_{a}^{\mathrm{el}}+\mathrm{k}_{a}^{\mathrm{raw}}$, the per-period cost of raw and pure water production can be written

$\mathrm{k}_{\mathrm{t}}^{\mathrm{raw}}=\mathrm{k}_{\mathrm{t}}^{\mathrm{pure}}=\sum_{a \in \mathcal{A}_{\mathrm{pr}}} \mathrm{k}_{a \mathrm{t}}^{\mathrm{raw}} \mathrm{Q}_{a \mathrm{t}}+\sum_{a \in \mathcal{A}_{\mathrm{pp}}} \mathrm{k}_{a \mathrm{t}}^{\mathrm{el}} \frac{\rho \mathrm{g} \Delta \mathrm{H}_{a \mathrm{t}} \mathrm{Q}_{a \mathrm{t}}}{\eta_{a}\left(\mathrm{Q}_{a \mathrm{t}}\right)}$.

\subsection{NLP Formulation}

The decision vector of time step $\mathrm{t}$ consists of node pressures $\mathrm{H}_{\mathrm{jt}}$, arc flows $\mathrm{Q}_{a t}$, and pressure differences $\Delta \mathrm{H}_{a \mathrm{t}}$ across pumps and valves,

$$
x_{\mathrm{t}}=\left(\begin{array}{c}
\left\{\mathrm{H}_{\mathrm{jt}}\right\}_{\mathrm{j} \in \mathcal{N}} \\
\left\{\mathrm{Q}_{a \mathrm{t}}\right\}_{a \in \mathcal{A}} \\
\left\{\Delta \mathrm{H}_{a \mathrm{t}}\right\}_{a \in \mathcal{A}_{\mathrm{pu}} \cup \mathcal{A}_{\mathrm{v} 1}}
\end{array}\right) \in \mathbf{R}^{n}, n=|\mathcal{N}|+|\mathcal{A}|+\left|\mathcal{A}_{\mathrm{pu}} \cup \mathcal{A}_{\mathrm{vl}}\right|,
$$

yielding the NLP decision vector

$$
x=\left(x_{1}, \ldots, x_{\mathrm{T}}\right) \in \mathbf{R}^{\mathrm{N}}, \quad \mathrm{N}=n \mathrm{~T} .
$$

We do not make a distinction between state and control variables here, and fixed initial values $\mathrm{x}_{0}$ are not included in $x$.

The equality constraints in each time step comprise one equation per network element (node or arc),

$$
\mathrm{c}_{\mathrm{t}}^{\mathcal{E}}\left(x_{\mathrm{t}-1}, x_{\mathrm{t}}\right)=\left(\begin{array}{c}
\left\{\mathrm{c}_{\mathrm{jt}}^{\text {flow }}\left(x_{\mathrm{t}}\right)\right\}_{\mathrm{j} \in \mathcal{N}_{\mathrm{jc}}} \\
\left\{\mathrm{c}_{\mathrm{jt}}^{\text {head }}\left(x_{\mathrm{t}}\right)\right\}_{\mathrm{j} \in \mathcal{N}_{\mathrm{rs}}} \\
\left\{\mathrm{c}_{\mathrm{jt}}^{\text {flow }}\left(x_{\mathrm{t}-1}, x_{\mathrm{t}}\right)\right\}_{\mathrm{j} \in \mathcal{N}_{\mathrm{ik}}} \\
\left\{\mathrm{c}_{a \mathrm{t}}^{\text {loss }}\left(x_{\mathrm{t}}\right)\right\}_{a \in \mathcal{A}_{\mathrm{pi}}} \\
\left\{\mathrm{c}_{a \mathrm{t}}^{\text {diff }}\left(x_{\mathrm{t}}\right)\right\}_{a \in \mathcal{A}_{\mathrm{pu}} \cup \mathcal{A}_{\mathrm{vl}}}
\end{array}\right) \in \mathbf{R}^{|\mathcal{N}|+|\mathcal{A}|},
$$

yielding

$$
\mathfrak{c}^{\mathcal{E}}(x)=\left(\begin{array}{c}
\mathrm{c}_{1}^{\mathcal{E}}\left(x_{0}, x_{1}\right) \\
\vdots \\
\mathrm{c}_{\mathrm{T}}^{\mathcal{E}}\left(x_{\mathrm{T}-1}, x_{\mathrm{T}}\right)
\end{array}\right)=0
$$

The number of variables and constraints per time step can be reduced by $\left|\mathcal{N}_{\text {rs }}\right|$ if the constant reservoir pressures are treated as parameters. In any case, there are $\left|\mathcal{A}_{\mathrm{pu}} \cup \mathcal{A}_{\mathrm{vl}}\right|$ degrees of freedom per time step corresponding to the number of controlled network elements.

The inequality constraints are comprised of upper and lower range constraints and simple bounds on all variables,

$$
\mathrm{c}^{\mathcal{R}}(x) \in\left[\mathrm{c}^{-}, \mathrm{c}^{+}\right], \quad x \in\left[x^{-}, x^{+}\right],
$$

with range constraints

$$
\mathrm{c}^{\mathcal{R}}(x)=\left(\begin{array}{c}
\mathrm{c}_{1}^{\mathcal{R}}\left(x_{0}, x_{1}\right) \\
\vdots \\
\mathrm{c}_{\mathrm{T}}^{\mathcal{R}}\left(x_{\mathrm{T}-1}, x_{\mathrm{T}}\right) \\
\left\{\mathrm{c}_{a}^{\mathrm{day}}(x)\right\}_{a \in \mathcal{A}_{p o}}
\end{array}\right)
$$

The components of $c^{\mathcal{R}}$ in each time step include the nontrivial inequalities from the pumps and valves,

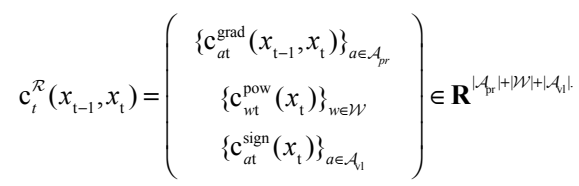

Note that the daily discharge limit in waterworks outlets depends on all decision vectors $x_{t}$ and that the tank flow balances and the gradient constraints in the raw water pumps depend on the current and previous decision vectors $\mathrm{x}_{\mathrm{t}}, \mathrm{x}_{\mathrm{t}-1}$; 
all other constraints only depend on the current decision vector $\mathrm{x}_{\mathrm{t}}$.

Finally, the separable objective can be written as

$$
\mathrm{f}(x)=\sum_{\mathrm{t}=1}^{\mathrm{T}} \mathrm{f}\left(x_{\mathrm{t}}\right)=\sum_{\mathrm{t}=1}^{\mathrm{T}}\left[\mathrm{f}_{\mathrm{t}}^{\text {raw }}\left(x_{\mathrm{t}}\right)+\mathrm{f}_{\mathrm{t}}^{\text {pure }}\left(x_{\mathrm{t}}\right)\right]
$$

where $f_{t}^{\text {raw }}$ and $f_{t}^{\text {pure }}$ are given according to (10) and (11) as

$$
\begin{aligned}
& \mathrm{f}_{\mathrm{t}}^{\text {raw }}\left(x_{\mathrm{t}}\right)=\sum_{a \in \mathcal{A}_{\mathrm{pc}}} \mathrm{f}_{a \mathrm{t}}^{\mathrm{raw}}\left(\mathrm{Q}_{a \mathrm{t}}\right)=\sum_{a \in \mathcal{A}_{\mathrm{pr}}}\left(w_{\mathrm{raw}, a} \mathrm{k}_{\mathrm{el}, a \mathrm{t}}+\mathrm{k}_{\mathrm{raw}, a \mathrm{t}}\right) \mathrm{Q}_{a \mathrm{t}} \Delta \mathrm{t}, \\
& \mathrm{f}_{\mathrm{t}}^{\text {pure }}\left(x_{\mathrm{t}}\right)=\sum_{a \in \mathcal{A}_{\mathrm{pc}}} \mathrm{f}_{a \mathrm{t}}^{\text {pure }}\left(\mathrm{Q}_{a \mathrm{t}}, \Delta \mathrm{H}_{a \mathrm{t}}\right)=\sum_{a \in \mathcal{A}_{\mathrm{pp}}} \mathrm{k}_{\mathrm{el}, a \mathrm{t}} \frac{\rho \mathrm{g} \Delta \mathrm{H}_{a \mathrm{t}} \mathrm{Q}_{a \mathrm{t}}}{\eta_{a}\left(\mathrm{Q}_{a \mathrm{t}}\right)} \Delta \mathrm{t} .
\end{aligned}
$$

Thus we obtain a highly structured NLP model in standard form:

$$
\underset{\mathrm{x}}{\operatorname{Minimize}} \mathrm{f}(x) \text { subject to } \mathrm{c}^{\mathcal{E}}(x)=0, \mathrm{c}^{\mathcal{J}}(x) \geq 0,
$$

where

$$
\mathrm{c}^{\mathcal{J}}(x)=\left(\begin{array}{c}
\mathrm{c}^{\mathcal{R}}(x)-\mathrm{c}^{-} \\
\mathrm{c}^{+}-\mathrm{c}^{\mathcal{R}}(x) \\
x-x^{-} \\
x^{+}-x
\end{array}\right) .
$$

\section{CONVERGENCE ACCELERATION}

One of the primary goals in developing the optimization approach presented here is to achieve acceptable response times for daily planning. Since we are restricted to work with general purpose NLP solvers available under GAMS, exploiting the characteristic NLP structure by developing special algorithms is not an option. We have to rely on convergence enhancement and other techniques. A suitable model formulation and a special initialization strategy for the iterative solution have turned out to be the most effective measures for convergence acceleration.

\subsection{Model Smoothness}

The objective and constraints in our model are all twice continuously differentiable $\left(\mathrm{C}^{2}\right)$, except for the pipe friction loss $\Delta \mathrm{H}(\mathrm{Q})=\mathrm{r}(\mathrm{Q}) \mathrm{Q}|\mathrm{Q}|$. In the piecewise quadratic $\mathrm{PKr}$ model $\Delta \mathrm{H}^{\mathrm{PKr}}$, the second order derivative has respective constant values $-2 \mathrm{r}^{\mathrm{PKr}}$ and $+2 \mathrm{r}^{\mathrm{PKr}}$ for $\mathrm{Q}<0$ and $\mathrm{Q}>0$, producing a jump discontinuity at $\mathrm{Q}=0$. Thus $\Delta \mathrm{H}^{\mathrm{PKr}}$ is $\mathrm{C}^{1}$ only. The more accurate HP-PC model $\Delta \mathrm{H}^{\mathrm{HP}-\mathrm{PC}}$ is not even continuous at the transition from laminar to turbulent flow [41].

The available solvers use derivatives up to first order (MINOS) or second order (CONOPT and SNOPT); numerical difficulties must therefore be expected on a $\mathrm{C}^{1}$ (or even less smooth) model whenever the flow variables traverse discontinuities between subsequent NLP iterations. This will typically happen during the initial phase of the iterative solution (i. e., far from the optimum, where large steps are taken), whereas it is less likely during the final phase of local convergence.

In order to avoid such numerical difficulties, we recommend the following smoothed $\mathrm{PKr}$ model as a global approximation of the pipe friction loss,

$$
\Delta \mathrm{H}_{a}^{\mathrm{PKrs}}(\mathrm{Q})=\mathrm{r}_{a}^{\mathrm{PKr}}\left(\sqrt{\mathrm{Q}^{2}+\mathrm{a}_{a}^{2}}+\mathrm{b}_{a}+\frac{\mathrm{c}_{a}}{\sqrt{\mathrm{Q}^{2}+\mathrm{d}_{a}^{2}}}\right) \mathrm{Q} .
$$

The parameters $\mathrm{a}_{a}>0$ and $\mathrm{d}_{a}>0$ can be selected to match a desired slope at $\mathrm{Q}=0$ and to balance the relative contributions of the two square root terms, whereas $\mathrm{b}_{a}>0$ and $\mathrm{c}_{a}<0$ depend on the pipe dimensions. They are determined in such a way that, asymptotically for $|\mathrm{Q}| \rightarrow \infty$, the law of Prandtl-Colebrook is approximated up to second order [41],

$$
\mathrm{b}_{a}=2 \delta_{a}, \quad \mathrm{c}_{a}=\left(\ln \beta_{a}+1\right) \delta_{a}^{2}-\frac{\mathrm{a}_{a}^{2}}{2},
$$

where

$$
\alpha_{a}=\frac{2.51}{4 /\left(\pi \mathrm{d}_{a}\right)}, \quad \beta_{a}=\frac{\mathrm{k}_{a} / \mathrm{d}_{a}}{3.71}, \quad \delta_{a}=\frac{2 \alpha_{a}}{\beta_{a} \ln 10} .
$$

If accuracy requirements are moderate, the PKrs model can be simplified by setting $\mathrm{c}_{a}=0$ or even $\mathrm{b}_{a}=\mathrm{c}_{a}=0$. This may be appropriate, for instance, for saving computational effort during early NLP iterations.

The numerical effect of the smoothing heavily depends on other circumstances. Computational experiments show that, on the test configuration, the smoothing yields significant convergence improvements for CONOPT and SNOPT (the SQP methods) with default initialization heuristics, whereas MINOS (the augmented Lagrangian method) is hardly affected at all. Moreover, SNOPT is slightly faster than MINOS on average. Interestingly, the advantage of the $\mathrm{C}^{2}$ PKrs model over the $\mathrm{C}^{1} \mathrm{PKr}$ model disappears when we introduce the SLP-based initialization scheme of Section 2.2; now MINOS performs equally well on both formulations, and always better than SNOPT. Another change in the picture occurs when we switch to the much larger main network model. Here the smoothing is beneficial for both solvers, with MINOS still outperforming SNOPT on average. (Apparently, due to rapid convergence within about 20 major iterations, the BFGS updates in SNOPT cannot build up sufficient curvature information to give an advantage). In practice, we therefore use MINOS on the $\mathrm{C}^{2}$ model.

\subsection{Initial Estimates}

Computational experiments with artificially perturbed optimal solutions (we added $10 \%$ white noise) confirm the expectation that rapid convergence can be achieved when the initial iterate is close to a solution. We have devised an automatic initialization scheme based on LP approximations of the NLP model in order to exploit this fact. Such approximations are rather crude but quickly solvable with standard LP software (we use CPLEX), so that physically meaningful initial estimates are generated with little effort. If the LP approximation is repeated several times, it yields an initialization scheme of SLP type (sequential linear programming).

The basic idea of SLP approaches in the literature (cf. [42-44]) is to replace the expensive QP in SQP methods (sequential quadratic programming) by a simpler LP 
subproblem, which results in an estimate of the active set at little cost even for very large problems:

$$
\begin{array}{ll}
\underset{\mathrm{s}}{\operatorname{Minimize}} & \mathrm{g}_{\mathrm{k}}^{*} \mathrm{~s} \\
\text { subject to } & \mathrm{J}_{\mathrm{k}}^{\mathcal{E}} \mathrm{s}+\mathrm{c}_{\mathrm{k}}^{\mathcal{E}}=0, \\
& \mathrm{~J}_{\mathrm{k}}^{\mathcal{J}} \mathrm{s}+\mathrm{c}_{\mathrm{k}}^{\mathcal{J}} \geq 0, \\
& \|\mathrm{~s}\|_{\infty} \leq \delta .
\end{array}
$$

The trust region constraint is introduced here to ensure global convergence and to prevent unboundedness, and the LP data are generated as a standard linearization of the problem functions. Thus $g_{k}$ is the gradient of the objective, $\mathrm{c}_{\mathrm{k}}^{\mathcal{E}}, \mathrm{c}_{\mathrm{k}}^{\mathcal{J}}$ are the respective residuals of equality and inequality constraints, and $\mathrm{J}_{\mathrm{k}}^{\mathcal{E}}, \mathrm{J}_{\mathrm{k}}^{\mathcal{J}}$ are the associated Jacobians:

$$
\begin{aligned}
\mathrm{g}_{\mathrm{k}}=\nabla \mathrm{f}\left(x^{\mathrm{k}}\right), & \mathrm{c}_{\mathrm{k}}^{\mathcal{E}}=\mathrm{c}^{\mathcal{E}}\left(x_{\mathrm{k}}\right), & \mathrm{J}_{\mathrm{k}}^{\mathcal{E}}=\nabla \mathrm{c}^{\mathcal{E}}\left(x^{\mathrm{k}}\right)^{*}, \\
& \mathrm{c}_{\mathrm{k}}^{\mathcal{J}}=\mathrm{c}^{\mathcal{J}}\left(x_{\mathrm{k}}\right), & \mathrm{J}_{\mathrm{k}}^{\mathcal{J}}=\nabla \mathrm{c}^{\mathcal{J}}\left(x^{\mathrm{k}}\right)^{*} .
\end{aligned}
$$

The LP solution $\mathrm{s}^{\mathrm{k}}$ serves to determine a working set of currently active constraints, based on which a better second order step is usually calculated. Only if this fails, $\mathrm{s}^{\mathrm{k}}$ is taken as the step direction for the SLP.

The LP (12)-(15) may be infeasible even if the NLP is feasible; it is therefore appropriate to minimize the $\ell_{1}$ penalty function instead, subject only to the trust region constraint,

Minimize $\ell_{1}(\mathrm{~s}, \rho)$ subject to $\|\mathrm{s}\|_{\infty} \leq \delta$,

where

$$
\begin{aligned}
\ell_{1}(\mathrm{~s}, \rho) & :=\mathrm{g}_{\mathrm{k}}^{*} \mathrm{~s}+\rho\left\|\mathrm{J}_{\mathrm{k}}^{\mathcal{E}} \mathrm{s}+\mathrm{c}_{\mathrm{k}}^{\mathcal{E}}\right\|_{1}+\rho\left\|\min \left(\mathrm{J}_{\mathrm{j}}^{\mathcal{J}} \mathrm{s}+\mathrm{c}_{\mathrm{k}}^{\mathcal{J}}, 0\right)\right\|_{1} \\
& =\mathrm{g}_{\mathrm{k}}^{*} \mathrm{~s}+\rho \sum_{\mathrm{i} \in \mathcal{E}}\left|\mathrm{J}_{\mathrm{k}}^{\mathrm{i}} \mathrm{s}+\mathrm{c}_{\mathrm{k}}^{\mathrm{i}}\right|+\rho \sum_{\mathrm{i} \in \mathcal{J}}\left|\min \left(\mathrm{J}_{\mathrm{k}}^{\mathrm{i}} \mathrm{s}+\mathrm{c}_{\mathrm{k}}^{\mathrm{i}}, 0\right)\right| .
\end{aligned}
$$

For the numerical solution, the nonsmooth $\ell_{1}$ problem is finally converted to the LP form by standard techniques (see, e.g., [45]), yielding the problem

$$
\begin{array}{ll}
\underset{\mathrm{s}, \mathrm{s}_{+}^{\mathcal{E}}, s_{-}^{\mathcal{E}}, \mathrm{s}_{-}^{\mathcal{J}}}{\operatorname{sini}} & \mathrm{g}_{\mathrm{k}}^{*} \mathrm{~s}+\rho \mathrm{e}^{*}\left(\mathrm{~s}_{+}^{\mathcal{E}}+\mathrm{s}_{-}^{\mathcal{E}}\right)+\rho \mathrm{e}^{*} \mathrm{~s}_{-}^{\mathcal{J}} \\
\text { subject to } & \mathrm{J}_{\mathrm{k}}^{\mathcal{E}} \mathrm{s}+\mathrm{c}_{\mathrm{k}}^{\mathcal{E}}-\mathrm{s}_{+}^{\mathcal{E}}+\mathrm{s}_{-}^{\mathcal{E}}=0, \quad \mathrm{~s}_{+}^{\mathcal{E}}, \mathrm{s}_{-}^{\mathcal{E}} \geq 0, \\
& \mathrm{~J}_{\mathrm{k}}^{\mathcal{J}} \mathrm{s}+\mathrm{c}_{\mathrm{k}}^{\mathcal{J}} \quad+\mathrm{s}_{-}^{\mathcal{J}} \geq 0, \quad \mathrm{~s}_{-}^{\mathcal{J}} \geq 0, \\
& \|\mathrm{~s}\|_{\infty} \leq \delta .
\end{array}
$$

The nonnegative slack variables $s_{+}^{\mathcal{E}}, \mathrm{s}_{-}^{\mathcal{E}}, \mathrm{s}_{-}^{\mathcal{J}}$ represent positive and negative violations of equality and inequality constraints, respectively, and e denotes the vector of ones in appropriate dimensions. We can easily see that the modified LP (17)-(20) is always feasible. Moreover, if the penalty parameter $\rho$ is sufficiently large, the slacks of an optimal solution vanish if and only if the original LP is feasible, in which case both problems yield the same optimal value for the step s.

Our problem-specific scheme differs from the general approach in several respects:

\subsubsection{Linearization}

Observe first that nonlinearities only arise in the pressure loss equations $\mathrm{c}_{a \mathrm{t}}^{\text {loss }}$, in the valve constraints $\mathrm{c}_{a \mathrm{t}}^{\text {sign }}$, and in the objective. These nonlinearities are handled as follows.

(1) The PKr friction model is used, and the absolute volumetric flow rates $\left|\mathrm{Q}_{a t}\right|$ are replaced by constant parameters $\overline{\mathrm{Q}}_{a \mathrm{t}}>0$. The pressure loss (6) then reads

$$
\mathrm{H}_{\mathrm{jt}}-\mathrm{H}_{\mathrm{it}}-\mathrm{r}_{a}^{\mathrm{PKr}} \overline{\mathrm{Q}}_{a \mathrm{t}} \mathrm{Q}_{a \mathrm{t}}=0 .
$$

For the parameter $\overline{\mathrm{Q}}_{a \mathrm{t}}$ we use a heuristic initial estimate defined as a constant multiple of the pipe diameter, $\overline{\mathrm{Q}}_{a \mathrm{t}}^{0}=\overline{\mathrm{cd}}_{a}$. (In practice, a reasonable value may be available from optimal solutions of the past). In iteration $k$, the flow components $\mathrm{Q}_{a \mathrm{t}}^{\mathrm{k}}$ of the LP solution are then used to update the parameter values,

$$
\overline{\mathrm{Q}}_{a \mathrm{t}}^{\mathrm{k}+1}=\alpha \overline{\mathrm{Q}}_{a \mathrm{t}}^{\mathrm{k}}+(1-\alpha)\left|\mathrm{Q}_{a \mathrm{t}}^{\mathrm{k}}\right|,
$$

where we choose $\alpha=0.6$ as weighting factor in the convex combination.

(2) If we temporarily assume that the direction of flow is known in all valves, the sign condition is replaced by two simple bounds,

$$
\mathrm{Q}_{a \mathrm{t}} \geq 0, \Delta \mathrm{H}_{a \mathrm{t}} \geq 0 \text { or } \mathrm{Q}_{a \mathrm{t}} \leq 0, \Delta \mathrm{H}_{a \mathrm{t}} \leq 0 .
$$

The dual LP solution then yields directional information for the next LP iteration: if any of the simplified constraints are binding, the sign of both constraints can be switched on the assumption that the chosen direction of flow was not optimal.

The nonlinear term $\Delta \mathrm{H}_{a t} \mathrm{Q}_{a t} / \eta\left(\mathrm{Q}_{a t}\right)$ in the pump efficiency model entering the cost function is handled as follows: the pressure difference $\Delta \mathrm{H}_{a t}$ is replaced by a constant parameter that is iteratively updated like $\overline{\mathrm{Q}}_{a \mathrm{t}}$. The quotient $\mathrm{Q}_{a \mathrm{t}} / \mathrm{\eta}\left(\mathrm{Q}_{a \mathrm{t}}\right)$ is approximated by a strictly increasing convex piecewise linear function of $\mathrm{Q}_{a t}$ that consists of three segments and starts at the origin.

Our LP is a local approximation of the NLP yielding the iterate $\mathrm{x}^{\mathrm{k}}$, rather than a local linearization yielding a step direction $\mathrm{s}^{\mathrm{k}}$ at the given iterate. Moreover, we do not use any second order information.

\subsubsection{Trust Region}

We do not impose a trust region constraint in addition to the bounds on all variables, since we are not interested in global or local convergence properties of the SLP method; we only want to get a cheap initial estimate for the NLP iteration instead. In practical computations we usually perform three SLP-type steps before switching to the fully nonlinear model. According to our experience (based on a large number of numerical experiments), this yields the best performance for the network of Berliner Wasserbetriebe.

\subsubsection{Penalty}

The $\ell_{1}$ penalty approach ensuring feasibility is only applied to selected constraints, namely to the pressure limits 
at pressure measurement points and at the outlets of waterworks and pumping stations. These constraints are relaxed in the LP as well as in the NLP model.

A relaxation of all inequality constraints is applied in a second version of our operative planning model. This version is used after physical modifications of the network, in order to detect potential infeasibilities caused by errors in the mathematical formulation or input data.

\subsubsection{Remarks}

A pure SLP approach has also been tested. The performance was generally inferior to the combined LP/NLP approach; often the iteration did not even converge.

Finally, we tried to catch the combinatorial aspects of the problem explicitly during the SLP initialization procedure by replacing the LP approximations by similar mixed-integer linear programs (MIP). Even with SOS Type 2 formulations of the piecewise linear approximation of the pressure loss equations (cf. [46-48]), the solution of the MIP subproblems took so long that no benefit could be achieved.

\section{COMBINATORIAL ISSUES}

Combinatorial aspects addressed here include the direction of the flow across valves and the switching of speed-controlled pumps. Further aspects that may occur in water networks include the switching of fixed-speed pumps [41] and the choice among alternative waterworks outlets. The latter involve purely integral decisions that cannot be treated satisfactorily in an NLP setting to date, although nonlinear programs with certain combinatorial structures (complementarity constraints and equilibrium constraints) have recently been studied and successfully solved by suitably extended NLP methods [49-53].

\subsection{Flow Direction across Valves}

The valve sign condition (5) has some undesirable properties at the origin, where the gradient vanishes and no constraint qualification holds. This reflects the geometry of the feasible set: consisting of two opposite closed quadrants, it has a disconnected interior and becomes itself disconnected if the origin is removed. One might think that the direction of the flow should therefore be introduced as a binary decision variable; however, a detailed analysis reveals that no numerical difficulties are to be expected as long as the gradient of the Lagrangian (projected into the relevant subspace) does not vanish at the origin. The latter condition is satisfied generically; there is therefore no need to reformulate the model.

\subsection{Pump Switching}

Computational experience shows that optimal solutions frequently exhibit undesirable pump switching at the waterworks outlets:

- $\quad$ short-term activation of a pump for just one or two periods;

- $\quad$ short-term deactivation of a pump for just one or two periods;
- alternating discharge: a certain flow rate is produced by two or more waterworks outlets alternating in time.

Operating schedules like these reduce the pump lifetime and require increased activity of the operators.

The specification of minimum up and down times is straightforward in a mixed-integer model. Let $\mathrm{Y}_{a \mathrm{t}} \in\{0,1\}$ designate the activity status of pump $a \in \mathcal{A}_{\mathrm{pp}}$; cf. [41]. Then the following linear inequality constraints, specified at $\mathrm{t}=$ $0, \ldots, \mathrm{T}-\mathrm{K}$, freeze the status for at least $\mathrm{K}$ periods after a switch:

$$
\mathrm{K}\left(\mathrm{Y}_{a, \mathrm{t}+1}-\mathrm{Y}_{a \mathrm{t}}\right) \leq \mathrm{Y}_{a, \mathrm{t}+1}+\cdots+\mathrm{Y}_{a, \mathrm{t}+\mathrm{K}} \leq 2 \mathrm{~K}\left(\mathrm{Y}_{a, \mathrm{t}+1}-\mathrm{Y}_{a \mathrm{t}}\right)+\mathrm{K}
$$

In a pure NLP setting it is unclear how to obtain a similar effect. Several mathematical and heuristic techniques have therefore been devised and tested in order to avoid unnecessary pump switching. These can be categorized into three major groups:

\section{(1) penalty approach;} linear, piecewise linear, and nonlinear constraints $\left(\mathrm{C}^{0}\right.$ or $\mathrm{C}^{2}$ );

\section{heuristics.}

In summary, most of the techniques either proved little successful or rather slow. However, we did find computationally cheap smooth constraints (group 2) that suppressed the undesired behavior, either with certainty (pump activation) or with high reliability (deactivation).

\subsubsection{Avoiding Short-Term Pump Activation}

As it turns out, activation of pumps for one or two periods can be prevented with certainty by suitable linear inter-temporal constraints. Formally, we wish to inhibit flow sequences of the types

(1) $\left(\mathrm{Q}_{\mathrm{t}}, \mathrm{Q}_{\mathrm{t}+1}, \mathrm{Q}_{\mathrm{t}+2}\right)=\left(0, \mathrm{Q}_{\mathrm{t}+1}, 0\right)$ with $\mathrm{Q}_{\mathrm{t}+1}>0$, or

(2) $\left(\mathrm{Q}_{\mathrm{t}}, \mathrm{Q}_{\mathrm{t}+1}, \mathrm{Q}_{\mathrm{t}+2}, \mathrm{Q}_{\mathrm{t}+3}\right)=\left(0, \mathrm{Q}_{\mathrm{t}+1}, \mathrm{Q}_{\mathrm{t}+2}, 0\right)$ with $\mathrm{Q}_{\mathrm{t}+1}, \mathrm{Q}_{\mathrm{t}+2}>0$.

The basic idea is to prevent excessive concavity of the piecewise constant flow rate profiles (1) and (2) by placing appropriate lower bounds on their discrete curvatures. In case (1), such a condition may be formulated as

$\mathrm{Q}_{\mathrm{t}}-2 \mathrm{Q}_{\mathrm{t}+1}+\mathrm{Q}_{\mathrm{t}+2} \geq-\mathrm{c}_{1}\left(\mathrm{Q}_{\mathrm{t}}+\mathrm{Q}_{\mathrm{t}+1}+\mathrm{Q}_{\mathrm{t}+2}\right), \mathrm{t}=0, \ldots, \mathrm{T}-2$,

where $c_{1}>0$ is a constant parameter. The flow-dependent right-hand side allows for larger values of the concavity with increasing total flow. A suitable range for the value of the parameter $c_{1}$ is determined as follows. In the case of interest, $\mathrm{Q}_{\mathrm{t}}=\mathrm{Q}_{\mathrm{t}+2}=0$, condition (21) yields

$$
-2 \mathrm{Q}_{\mathrm{t}+1} \geq-\mathrm{c}_{1} \mathrm{Q}_{\mathrm{t}+1}
$$

so that one must choose $c_{1}<2$ to force $\mathrm{Q}_{\mathrm{t}+1}$ to zero, as desired. On the other hand, we do not wish to rule out otherwise feasible pump operation: if $\mathrm{c}_{1}$ is chosen unreasonably small, then condition (21) will become too restrictive. This can immediately be seen in the equivalent form

$\mathrm{Q}_{\mathrm{t}+1} \leq \frac{1+\mathrm{c}_{1}}{2-\mathrm{c}_{1}}\left(\mathrm{Q}_{\mathrm{t}}+\mathrm{Q}_{\mathrm{t}+2}\right)$ 
which implies, for instance, $\mathrm{Q}_{\mathrm{t}+1} \leq \frac{1}{2}\left(\mathrm{Q}_{\mathrm{t}}+\mathrm{Q}_{\mathrm{t}+2}\right)$ if $\mathrm{c}_{1}=0$, and $\mathrm{Q}_{\mathrm{t}+1}=0$ for all $\mathrm{t}$ if $\mathrm{c}_{1} \leq-1$. In order to find a lower bound on $\mathrm{c}_{1}$, we rewrite (21) as

$$
\left(1+c_{1}\right)\left(Q_{t}+Q_{t+2}\right)-\left(2-c_{1}\right) Q_{t+1} \geq 0
$$

and determine the minimum of the left-hand expression over the nontrivial feasible flow sequences,

$\left\{\mathrm{Q}_{\mathrm{t}}, \mathrm{Q}_{\mathrm{t}+1}, \mathrm{Q}_{\mathrm{t}+2} \in\{0\} \cup\left[\mathrm{Q}^{-}, \mathrm{Q}^{+}\right]: \mathrm{Q}_{\mathrm{t}} \neq 0\right.$ or $\left.\mathrm{Q}_{\mathrm{t}+2} \neq 0\right\}$.

This yields

$$
\left(1+\mathrm{c}_{1}\right) \mathrm{Q}^{-}-\left(2-\mathrm{c}_{1}\right) \mathrm{Q}^{+} \geq 0,
$$

which is realized by the extremal flow sequences

Letting

$$
\left(0, \mathrm{Q}^{+}, \mathrm{Q}^{-}\right) \text {and }\left(\mathrm{Q}^{-}, \mathrm{Q}^{+}, 0\right) \text {. }
$$

$$
\alpha=\frac{\mathrm{Q}^{+}}{\mathrm{Q}^{-}}>1 \text { and } \beta_{1}=\frac{2 \alpha-1}{\alpha+1} \in\left(\frac{1}{2}, 2\right),
$$

the minimal left-hand expression above is finally seen to be nonnegative if and only if

$$
\mathrm{c}_{1} \in\left[\beta_{1}, 2\right) \text { where }\left[\beta_{1}, 2\right) \neq \varnothing .
$$

Similar reasoning for the two-period case (2) yields the restriction

$$
\begin{gathered}
\mathrm{Q}_{\mathrm{t}}-\mathrm{Q}_{\mathrm{t}+1}-\mathrm{Q}_{\mathrm{t}+2}+\mathrm{Q}_{\mathrm{t}+3} \geq-\mathrm{c}_{2}\left(\mathrm{Q}_{\mathrm{t}}+\mathrm{Q}_{\mathrm{t}+1}+\mathrm{Q}_{\mathrm{t}+2}+\mathrm{Q}_{\mathrm{t}+3}\right), \\
\mathrm{t}=0, \ldots, \mathrm{T}-3 .
\end{gathered}
$$

One must require $c_{2}<1$ here in order to prevent undesired pump activation, and a lower bound $\beta_{2}$ is obtained by the reformulation

$$
\left(1+\mathrm{c}_{2}\right)\left(\mathrm{Q}_{\mathrm{t}}+\mathrm{Q}_{\mathrm{t}+3}\right)-\left(1-\mathrm{c}_{2}\right)\left(\mathrm{Q}_{\mathrm{t}+1}+\mathrm{Q}_{\mathrm{t}+2}\right) \geq 0 .
$$

Minimizing the left-hand expression yields extremal flow sequences

$$
\left(0, \mathrm{Q}^{+}, \mathrm{Q}^{+}, \mathrm{Q}^{-}\right) \text {and }\left(\mathrm{Q}^{-}, \mathrm{Q}^{+}, \mathrm{Q}^{+}, 0\right) \text {, }
$$

and the condition

$$
\left(1+c_{2}\right) Q^{-}-\left(1-c_{2}\right)\left(2 Q^{+}\right) \geq 0 .
$$

Thus we finally get

$$
c_{2} \in\left[\beta_{2}, 1\right) \text { where } \beta_{2}=\frac{2 \alpha-1}{2 \alpha+1} \in\left(\frac{1}{3}, 1\right) \text {, and }\left[\beta_{2}, 1\right) \neq \varnothing \text {. }
$$

In summary, the following linear inequalities prevent undesired pump activation for one or two periods with certainty without being too restrictive:

$\left(\mathrm{c}_{1}+1\right) \mathrm{Q}_{\mathrm{t}}+\left(\mathrm{c}_{1}-2\right) \mathrm{Q}_{\mathrm{t}+1}+\left(\mathrm{c}_{1}+1\right) \mathrm{Q}_{\mathrm{t}+2} \geq 0, \mathrm{c}_{1} \in\left(\frac{1}{2}, 2\right)$,

$\left(c_{2}+1\right) \mathrm{Q}_{\mathrm{t}}+\left(\mathrm{c}_{2}-1\right) \mathrm{Q}_{\mathrm{t}+1}+\left(\mathrm{c}_{2}-1\right) \mathrm{Q}_{\mathrm{t}+2}+\left(\mathrm{c}_{2}+1\right) \mathrm{Q}_{\mathrm{t}+3} \geq 0$, $\mathrm{c}_{2} \in\left(\frac{1}{3}, 2\right)$.

These restrictions are specified for each pump in almost all time steps, yielding the large number of $\mathrm{O}\left(\left|\mathcal{A}_{\mathrm{pu}}\right| \mathrm{T}\right)$ extra conditions. Despite this, no adverse effect on the computation time was observed on our problem instances.

\subsubsection{Avoiding Short-Term Deactivation of Pumps}

Linear restrictions in the spirit of (21) are unfortunately not useful if we want to avoid short-term deactivation: assume that $\left(\mathrm{Q}_{\mathrm{t}}, 0,0\right)$ and $\left(0,0, \mathrm{Q}_{\mathrm{t}+2}\right)$ are feasible and all feasible sequences satisfy the constraint

$$
\mathrm{aQ}_{\mathrm{t}}+\mathrm{bQ}_{\mathrm{t}+1}+\mathrm{cQ}_{\mathrm{t}+2}+\mathrm{d} \geq 0 \text {. }
$$

Although the sequence $\left(\mathrm{Q}_{\mathrm{t}}, 0, \mathrm{Q}_{\mathrm{t}+2}\right)$ is forbidden, it satisfies the same constraint. The asymmetry arises from the fact that during activation the initial and final flow rates are both exactly known and identical, $\mathrm{Q}_{\mathrm{t}}=\mathrm{Q}_{\mathrm{t}+2}=0$, whereas only $\mathrm{Q}_{\mathrm{t}+1}=0$ is known during deactivation. In general, $\mathrm{Q}_{\mathrm{t}}$ and $Q_{t+2}$ are neither known nor identical in the latter case.

In order to inhibit short-term deactivation, we suggest to specify a certain fraction of the minimum of the enclosing values as lower bound on the intermediate flow rate; we arrive at the piecewise linear constraint

$$
\mathrm{Q}_{\mathrm{t}+1} \geq \mathrm{c} \min \left(\mathrm{Q}_{\mathrm{t}}, \mathrm{Q}_{\mathrm{t}+2}\right), \mathrm{t}=0, \ldots, \mathrm{T}-2,
$$

with an appropriate parameter range of $\mathrm{c} \in(0,1]$. Although doing the job, this formulation slows down convergence dramatically, which is not surprising since the minimum function is not differentiable but only continuous $\left(\mathrm{C}^{0}\right)$. Using the standard reformulation in terms of the absolute value function,

$$
\mathrm{Q}_{\mathrm{t}+1} \geq \frac{\mathrm{c}}{2}\left(\mathrm{Q}_{\mathrm{t}}+\mathrm{Q}_{\mathrm{t}+2}-\left|\mathrm{Q}_{\mathrm{t}}-\mathrm{Q}_{\mathrm{t}+2}\right|\right)
$$

one can now apply the smoothing $|\mathrm{x}|=\sqrt{x^{2}} \approx \sqrt{x^{2}+\alpha^{2}}$ to obtain the $\mathrm{C}^{2}$ formulation

$$
Q_{t+1} \geq \frac{c}{2}\left(Q_{t}+Q_{t+2}-\sqrt{\left(Q_{t}-Q_{t+2}\right)^{2}+\alpha^{2}}\right) .
$$

We finally redefine $\mathrm{c}$ in order to arrive at the nonlinear inequality

$\mathrm{Q}_{\mathrm{t}+1}-\mathrm{c}\left(\mathrm{Q}_{\mathrm{t}}+\mathrm{Q}_{\mathrm{t}+2}-\sqrt{\left(\mathrm{Q}_{1}-\mathrm{Q}_{\mathrm{t}+2}\right)^{2}+\alpha^{2}}\right) \geq 0, \quad \mathrm{c} \in\left(0, \frac{1}{2}\right]$.

The two-period version consists of two similar inequalities with identical parameters,

$$
\mathrm{Q}_{\mathrm{t}+\mathrm{i}} \geq \mathrm{c} \min \left(\mathrm{Q}_{\mathrm{t}}, \mathrm{Q}_{\mathrm{t}+3}\right), \quad \mathrm{i}=1,2, \quad \mathrm{t}=0, \ldots, \mathrm{T}-3,
$$

yielding the smooth reformulation

$$
\mathrm{Q}_{\mathrm{t}+i}-\mathrm{c}\left(\mathrm{Q}_{\mathrm{t}}+\mathrm{Q}_{\mathrm{t}+3}-\sqrt{\left(\mathrm{Q}_{1}-\mathrm{Q}_{\mathrm{t}+3}\right)^{2}+\alpha^{2}}\right) \geq 0, \quad \mathrm{c} \in\left(0, \frac{1}{2}\right], \quad \mathrm{i}=1,2 .
$$

Note that the constraints (23), (24) are always compatible with the flow bounds and flow gradient bounds.

\section{MODEL REDUCTION}

Due to excessive computation times with the main network (even in the case of rapid convergence), the need for a systematic size reduction of the network graph arose. Such a reduction is performed by preprocessing before the optimization; it is based solely on static network data, so that a single reduced graph is used over the entire horizon.

The reduction leads to simplified models for the pipe friction loss, where we calculate the leading coefficient from the $\mathrm{PKr}$ model to ensure asymptotically correct friction loss for large flow values $|\mathrm{Q}|$. Appropriate smoothing is then introduced for small flow values. 


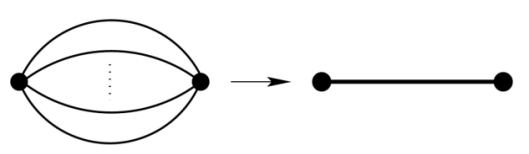

Fig. (3). Collapsing parallel pipes.

\subsection{Parallel Pipes}

It is not uncommon for municipal water networks to contain pairs of nodes that are connected by several "parallel" pipes. In the network model, such pipe ensembles can be replaced by a single pipe (see Fig. 3), which is hydraulically equivalent if the loss coefficients $r_{v}$ are flowindependent ( $\mathrm{PKr}$ model). Consider a collection of $\mathrm{n}$ parallel pipes with total flow rate

$\mathrm{Q}=\mathrm{Q}_{1}+\cdots+\mathrm{Q}_{\mathrm{n}}$.

All the flows $\mathrm{Q}$ and $\mathrm{Q}_{v}$ have the same direction and $\mathrm{a}$ common pressure difference,

$\Delta \mathrm{H}=\mathrm{rQ}|\mathrm{Q}|=\mathrm{r}_{v} \mathrm{Q}_{v}\left|\mathrm{Q}_{v}\right|, \quad v=1, \ldots, \mathrm{n}$.

The fictitious loss coefficient $r$ of the hydraulically equivalent pipe is readily calculated from (25) and (26). Assuming positive flows with no loss of generality, one obtains

$$
\sqrt{\frac{\Delta H}{r}}=Q=\sum_{v=1}^{n} Q_{v}=\sum_{v=1}^{n} \sqrt{\frac{\Delta H}{r_{v}}}
$$

and hence

$$
\frac{1}{\sqrt{\mathrm{r}}}=\sum_{\mathrm{v}=1}^{\mathrm{n}} \frac{1}{\sqrt{\mathrm{r}_{\mathrm{v}}}} \Leftrightarrow \mathrm{r}=\left(\sum_{\mathrm{v}=1}^{\mathrm{n}} \sqrt{\frac{\Delta \mathrm{H}}{\mathrm{r}_{\mathrm{v}}}}\right)^{-2}
$$

Conversely, with (26) the individual flows $\mathrm{Q}_{v}$ are recovered from the total flow as

$$
\mathrm{Q}_{\mathrm{v}}=\sqrt{\frac{\mathrm{r}}{\mathrm{r}_{\mathrm{v}}} \mathrm{Q} .}
$$

This is similar to parallel resistors in an electric circuit, except that the flow dependence here is quadratic rather than linear.

For a derivation of the parameters of the smooth approximation (2.1), the replacement pipe also needs fictitious geometric dimensions. We define the length as the average length of the original pipes, and the diameter such that the total pipe volumes agree,

$$
\mathrm{L}=\frac{1}{\mathrm{n}} \sum_{\mathrm{v}=1}^{\mathrm{n}} \mathrm{L}_{\mathrm{v}}, \mathrm{d}=\sqrt{\frac{1}{\mathrm{~L}} \sum_{\mathrm{v}=1}^{\mathrm{n}} \mathrm{L}_{\mathrm{v}} \mathrm{d}_{\mathrm{v}}^{2}}
$$

The roughness is finally chosen in such a way that $r$ is consistent with all dimensions according to (6) and (7),

$$
r=\frac{8 \mathrm{~L}}{\pi^{2} \mathrm{gd}^{5}}\left(2 \log \frac{\mathrm{k} / \mathrm{d}}{3.71}\right)^{-2}
$$

yielding

$$
k=3.71 d \times 10^{p}, \quad p=\sqrt{2 L /\left(\pi^{2} g d^{5} r\right)}
$$

From these values we readily obtain the required parameters b, c for the PKrs model.

\subsection{Pipe Sequences}

A sequence of $\mathrm{n}$ pipes traversing junction nodes $0, \ldots, \mathrm{n}$ can be collapsed if no other arcs are connected to the interior nodes $1, \ldots, \mathrm{n}-1$. In this case the interior nodes are eliminated, their demands $\mathrm{D}_{v}$ are distributed over the two boundary nodes, and the $\mathrm{n}$ pipes are replaced by a fictitious single pipe; (see Fig. (4)).

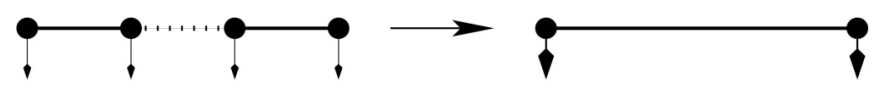

Fig. (4). Collapsing pipe sequences.

\subsubsection{Zero Interior Demands}

In the case of vanishing demands, pipes $1, \ldots, \mathrm{n}$ have identical flow rates, $\mathrm{Q}_{v}=\mathrm{Q}$, and a hydraulically equivalent model is obtained if and only if the loss coefficient $r$ of the fictitious pipe is defined as the sum of the individual loss coefficients,

$$
\mathrm{H}_{0}-\mathrm{H}_{\mathrm{n}}=\sum_{\mathrm{v}=1}^{\mathrm{n}} \mathrm{H}_{\mathrm{v}-1}-\mathrm{H}_{\mathrm{v}}=\sum_{\mathrm{v}=1}^{\mathrm{n}} \mathrm{r}_{\mathrm{v}} \mathrm{Q}_{\mathrm{v}}\left|\mathrm{Q}_{\mathrm{v}}\right|=\sum_{\mathrm{v}=1}^{\mathrm{n}} \mathrm{r}_{\mathrm{v}} \mathrm{Q}|\mathrm{Q}|=\mathrm{r} \mathrm{Q}|\mathrm{Q}|
$$

This is similar to serial resistors in an electric circuit, and it does not matter whether the coefficients $r_{v}$ are assumed to be flow-independent or not.

\subsubsection{Nonzero Interior Demands}

For arbitrary consumption demands it is impossible to construct a hydraulically equivalent reduced model. There are three reasons:

the symmetry with respect to the direction of the flow is broken in general: inflows of identical magnitudes at nodes 0 and $\mathrm{n}$ yield different absolute pressure differences;

the inflow may enter from both sides, adding up to the total interior demand;

the pressure difference does not depend quadratically on any linear combination of the flow rates $Q_{v}$, even with quadratic segment losses $\mathrm{r}_{v} \mathrm{Q}_{v}\left|\mathrm{Q}_{v}\right|$ (PKr model).

As it turns out, the best fictitious replacement pipe in this case is obtained as follows. With the notation $r_{k: 1}:=\sum_{v=k}^{1} r_{v}$, let $\mathrm{r}=\mathrm{r}_{1: \mathrm{n}}$ (as above), let $\mathrm{L}=\mathrm{L}_{1: \mathrm{n}}$, and split each interior demand $\mathrm{D}_{v}$ into fictitious demands $\left(\mathrm{r}_{v+1: \mathrm{n}} / \mathrm{r}\right) \mathrm{D}_{v}$ at node 0 and $\left(\mathrm{r}_{1: v} / \mathrm{r}\right) \mathrm{D}_{v}$ at node $\mathrm{n}$, according to the relation of friction losses to each endpoint:

$D_{0}^{\text {int }}:=\sum_{\mathrm{v}=1}^{\mathrm{n}-1} \frac{\mathrm{r}_{\mathrm{v}+1: \mathrm{n}}}{\mathrm{r}} \mathrm{D}_{\mathrm{v}}, \quad \mathrm{D}_{\mathrm{n}}^{\mathrm{int}}:=\sum_{\mathrm{v}=1}^{\mathrm{n}-1} \frac{\mathrm{r}_{\mathrm{l:v}}}{\mathrm{r}} \mathrm{D}_{\mathrm{v}}$

The actual inflow from node 0 and outflow to node $n, \mathrm{Q}_{1}$ and $\mathrm{Q}_{\mathrm{n}}$, are thus replaced with a common fictitious flow value, $\mathrm{Q}_{1}-\mathrm{D}_{0}^{\mathrm{int}}=\mathrm{Q}_{\mathrm{n}}+\mathrm{D}_{\mathrm{n}}^{\mathrm{int}}$.

As with parallel pipes (see Section 4.1), the diameter d and roughness $\mathrm{k}$ of the fictitious pipe are determined such that its loss coefficient $r$ is consistent with the PKr model. 
We will now see that one can do better than with such a single pipe replacement model. Consider the exact pressure loss in the pipe sequence according to the quadratic $\mathrm{PKr}$ model. Since the flow rates in successive pipes are related by

$$
\mathrm{Q}_{v+1}=\mathrm{Q}_{v}-\mathrm{D}_{v}, \quad v=1, \ldots, \mathrm{n}-1,
$$

we inductively get

$$
\mathrm{Q}_{v}=\mathrm{Q}_{1}-\overline{\mathrm{D}}_{\mathrm{v}}, \quad v=1, \ldots, \mathrm{n},
$$

where $\mathrm{Q}_{1}$ is the inflow from node 0 and $\overline{\mathrm{D}}_{\mathrm{v}}$ denotes the cumulative interior demand up to and including node $v-1$,

$$
\overline{\mathrm{D}}_{\mathrm{v}}=\mathrm{D}_{1: v-1}, \quad \mathrm{v}=1, \ldots, \mathrm{n} \text {. }
$$

(Note that $\overline{\mathrm{D}}_{1}=0$, giving total interior demand $\overline{\mathrm{D}}_{\mathrm{n}}=\mathrm{D}_{1}+\cdots+\mathrm{D}_{\mathrm{n}-1}$ ). Thus we obtain

$$
\mathrm{H}_{0}-\mathrm{H}_{\mathrm{n}}=\sum_{\mathrm{v}=1}^{\mathrm{n}} \mathrm{r}_{\mathrm{v}} \mathrm{Q}_{\mathrm{v}}\left|\mathrm{Q}_{\mathrm{v}}\right|=\sum_{\mathrm{v}=1}^{\mathrm{n}} \mathrm{r}_{\mathrm{v}}\left(\mathrm{Q}_{1}-\overline{\mathrm{D}}_{\mathrm{v}}\right)\left|\mathrm{Q}_{1}-\overline{\mathrm{D}}_{\mathrm{v}}\right| .
$$

\section{Left-Sided Inflow}

Consider first the case where $\mathrm{Q}_{1} \geq \overline{\mathrm{D}}_{\mathrm{n}}$ (that is, all flow directions in the pipe sequence are positive) and observe that the coefficients $r_{v} / r$ formally satisfy the properties of a probability distribution. Defining the spatial flow distribution vectors $\mathrm{Q}=\left(\mathrm{Q}_{1}, \ldots, \mathrm{Q}_{\mathrm{n}}\right)$ and similarly $\mathrm{D}=$ $\left(\bar{D}_{1}, \ldots, \bar{D}_{n}\right)$ etc., one obtains

$$
\begin{aligned}
\mathrm{H}_{0}-\mathrm{H}_{\mathrm{n}} & =\mathrm{r} \sum_{\mathrm{v}=1}^{\mathrm{n}} \frac{\mathrm{r}_{\mathrm{v}}}{\mathrm{r}} \mathrm{Q}_{\mathrm{v}}^{2}=\mathrm{rE}\left(\mathrm{Q}^{2}\right) \\
& =\mathrm{r}\left[\mathbf{E}(\mathrm{Q})^{2}+\left(\mathbf{E}\left(\mathrm{Q}^{2}\right)-\mathbf{E}(\mathrm{Q})^{2}\right)\right]=\mathrm{rE}(\mathrm{Q})^{2}+\mathrm{r} \operatorname{Var}(\mathrm{Q}) .
\end{aligned}
$$

The first term can be interpreted as the pressure loss of a weighted average flow rate with respect to the "probabilities" $r_{v} / r$,

$$
\sum_{\mathrm{v}=1}^{\mathrm{n}} \frac{\mathrm{r}}{\mathrm{r}} \mathrm{Q}_{\mathrm{v}}=\mathbf{E}(\mathrm{Q})=\mathbf{E}\left(\mathrm{Q}_{1}-\overline{\mathrm{D}}\right)=\mathrm{Q}_{1}-\mathbf{E}(\overline{\mathrm{D}}) .
$$

The second term can be interpreted as an additional pressure loss due to the variance of the individual flow rates, which equals the flow-independent variance of the accumulated demands,

$$
\mathbf{E}\left(Q^{2}\right)-\mathbf{E}(Q)^{2}=\operatorname{Var}(\mathrm{Q})=\operatorname{Var}\left(\mathrm{Q}_{1}-\overline{\mathrm{D}}\right)=\operatorname{Var}(\overline{\mathrm{D}}) .
$$

Since $\overline{\mathrm{D}}_{1}=0$, this variance vanishes if and only if all interior demands vanish.

\section{Right-Sided Inflow}

Consider next the situation for $\mathrm{Q}_{1} \leq 0$, which is similar to $\mathrm{Q}_{1} \geq \overline{\mathrm{D}}_{\mathrm{n}}$ except that the flow now has the opposite direction, and we have a pressure loss from node $\mathrm{n}$ to node 0 ,

$$
\mathrm{H}_{0}-\mathrm{H}_{\mathrm{n}}=-\mathrm{r} \mathbf{E}(\mathrm{Q})^{2}-\mathrm{rVar}(\mathrm{Q})=-\mathrm{r} \mathbf{E}(\mathrm{Q})^{2}-\mathrm{rVar}(\overline{\mathrm{D}}) .
$$

With the demand redistribution defined in (27), the fictitious pipe's flow rate is $\mathbf{E}(\mathrm{Q})$,

$$
\mathrm{Q}_{1}-\mathrm{D}_{0}^{\mathrm{int}}=\mathrm{Q}_{1}-\sum_{0<\mathrm{v}<\mu \leq \mathrm{n}} \frac{\mathrm{r}_{\mu}}{\mathrm{r}} \mathrm{D}_{\mathrm{v}}=\mathrm{Q}_{1}-\mathbf{E}(\mathrm{D})=\mathbf{E}(\mathrm{Q}),
$$

thus resulting precisely in the first term of the pressure loss (28) according to the PKr model. The constant variance term, however, cannot be obtained in this pipe model-a qualitative defect of the single pipe replacement (reason 3).
By symmetry, the relevant quantities above can also be expressed in terms of $\mathrm{Q}_{\mathrm{n}}$ rather than $\mathrm{Q}_{1}$. If we define

$$
\underline{\mathrm{D}}_{v}=\mathrm{D}_{v: \mathrm{n}-1}, v=1, \ldots, \mathrm{n},
$$

so that $\mathrm{Q}_{v}=\mathrm{Q}_{\mathrm{n}}+\underline{\mathrm{D}}_{v}$ with $\underline{\mathrm{D}}_{\mathrm{n}}=0$ and $\underline{\mathrm{D}}_{1}=\overline{\mathrm{D}}_{\mathrm{n}}$, this yields alternative representations for the actual in-and outflow,

$$
\begin{aligned}
\mathrm{Q}_{1}= & \mathrm{Q}_{1}-\overline{\mathrm{D}}_{1}=\mathrm{Q}_{\mathrm{n}}+\underline{\mathrm{D}}_{1}, \\
& \mathrm{Q}_{1}-\overline{\mathrm{D}}_{\mathrm{n}}=\mathrm{Q}_{\mathrm{n}}+\underline{\mathrm{D}}_{\mathrm{n}}=\mathrm{Q}_{\mathrm{n}},
\end{aligned}
$$

and for the (identical) fictitious in-and outflow,

$$
\mathrm{Q}_{1}-\mathrm{D}_{0}^{\text {int }}=\mathrm{Q}_{1}-\mathbf{E}(\overline{\mathrm{D}})=\mathbf{E}(\mathrm{Q})=\mathrm{Q}_{\mathrm{n}}+\mathbf{E}(\underline{\mathrm{D}})=\mathrm{Q}_{\mathrm{n}}+\mathrm{D}_{\mathrm{n}}^{\text {int }} .
$$

Two-Sided Inflow

A second, more serious qualitative defect arises when $\mathrm{Q}_{1}$ $\in\left(0, \overline{\mathrm{D}}_{\mathrm{n}}\right)$, or $-\mathbf{E}(\underline{\mathrm{D}})<\mathbf{E}(\mathrm{Q})<\mathbf{E}(\overline{\mathrm{D}})$ : in this case, we have inflows from both sides, and the total pressure difference $\mathrm{H}_{0}$ $-\mathrm{H}_{\mathrm{n}}$ depends on the location where the inflows meet in the pipe sequence. This location has minimal pressure within the sequence and occurs either at a unique node whose inflows are both smaller than the local demand, or possibly at a unique pair of nodes whose (one-sided) inflows equal the respective demands, yielding stagnant flow in between. Clearly, this situation cannot be modeled by a single replacement pipe with just one flow direction (reason 2). Without simplifications, the $\mathrm{PKr}$ friction model yields a piecewise quadratic dependence where the curvature has jump discontinuities at $\mathrm{Q}_{1}=\overline{\mathrm{D}}_{\mathrm{v}}\left(\right.$ or $\left.\mathrm{Q}_{\mathrm{n}}=\underline{\mathrm{D}}_{v}\right), v=1, \ldots, \mathrm{n}$.

Denoting the fictitious flow $\mathbf{E}(\mathrm{Q})$ as $\mathrm{Q}$ and the values $-\mathbf{E}(\overline{\mathrm{D}}),+\mathbf{E}(\underline{\mathrm{D}})$ as $\mathrm{D}^{-}, \mathrm{D}^{+}$, respectively, we suggest to use a global smoothing for the entire sequence by approximating the pressure difference for $\mathrm{Q} \in\left(\mathrm{D}^{-}, \mathrm{D}^{+}\right)$with the unique polynomial of degree five, which has $\mathrm{C}^{2}$ junctions with the outer pieces at $\mathrm{Q}=\mathrm{D}^{-}$and $\mathrm{Q}=\mathrm{D}^{+}$:

$$
\phi(\mathrm{Q})=\sum_{\mathrm{k}=0}^{5} \mathrm{c}_{\mathrm{k}} \mathrm{Q}^{\mathrm{k}},
$$

where the coefficients $c_{k}$ are obtained from a linear equation system representing the matching conditions. The resulting replacement model ("generalized pipe") has three benefits: the constant variance term is included, inflows from both sides are suitably modeled, and all discontinuities disappear. Letting $\mathrm{V}=\operatorname{Var}(\overline{\mathrm{D}})=\operatorname{Var}(\underline{\mathrm{D}})$, one thus gets a global $\mathrm{C}^{2}$ representation consisting of three pieces; (see Fig. (5)):

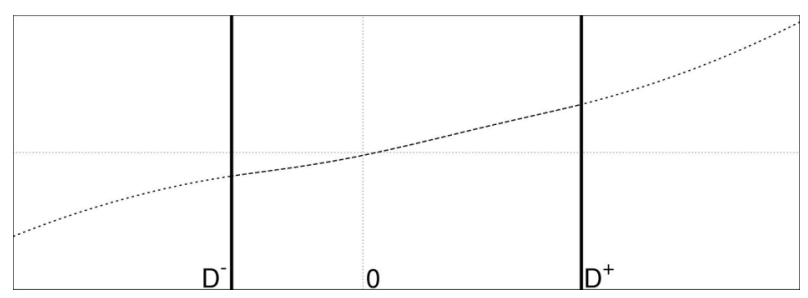

Fig. (5). Three-piece $\mathrm{C}^{2}$ model of pressure loss in a pipe sequence.

$$
H_{0}-H_{n}=\Delta H(Q)= \begin{cases}-r Q^{2}-r V, & Q \leq D^{-}, \\ r \phi(Q), & Q \in\left(D^{-}, D^{+}\right), \\ +r Q^{2}+r V, & Q \geq D^{+} .\end{cases}
$$




\subsection{Short Pipes}

The pressure loss along a short pipe is often negligible so that the pipe can be collapsed into a single node; see Fig. (6). Such collapsing may even be possible for entire subnetworks (consisting of junctions and sufficiently short pipes only), which is typical for residential or industrial areas.

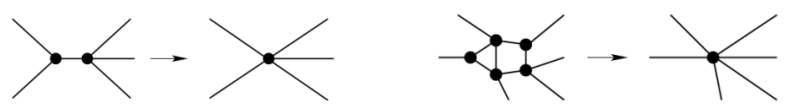

Fig. (6). Collapsing short pipes and subnetworks.

The following algorithm is used for collapsing subnetworks.

(1) Input: a subset of pipes that must not be removed from the graph, $\mathcal{A}_{0} \subset \mathcal{A}_{\mathrm{pi}}$, and the maximal length of a "short" pipe, $\mathrm{L}_{\max }$.

Determine the set of short pipes eligible for removal,

$$
\mathcal{A}_{\text {short }}=\left\{a \in \mathcal{A}_{\text {pi }} \backslash \mathcal{A}_{0}: \mathrm{L}_{a} \leq \mathrm{L}_{\text {max }}\right\} .
$$

Determine the network subgraph induced by $\mathcal{A}_{\text {short }}$, with connected components $\mathrm{G}_{1}=\left(\mathcal{N}_{1}, \mathcal{A}_{1}\right)$.

Collapse each connected component $\mathrm{G}_{1}$ to a single junction 1 having demand $\mathrm{D}_{1}$ :

$$
\mathrm{D}_{1}=\sum_{j \in \mathcal{N}_{\mathrm{t}}} \mathrm{D}_{\mathrm{j}} .
$$
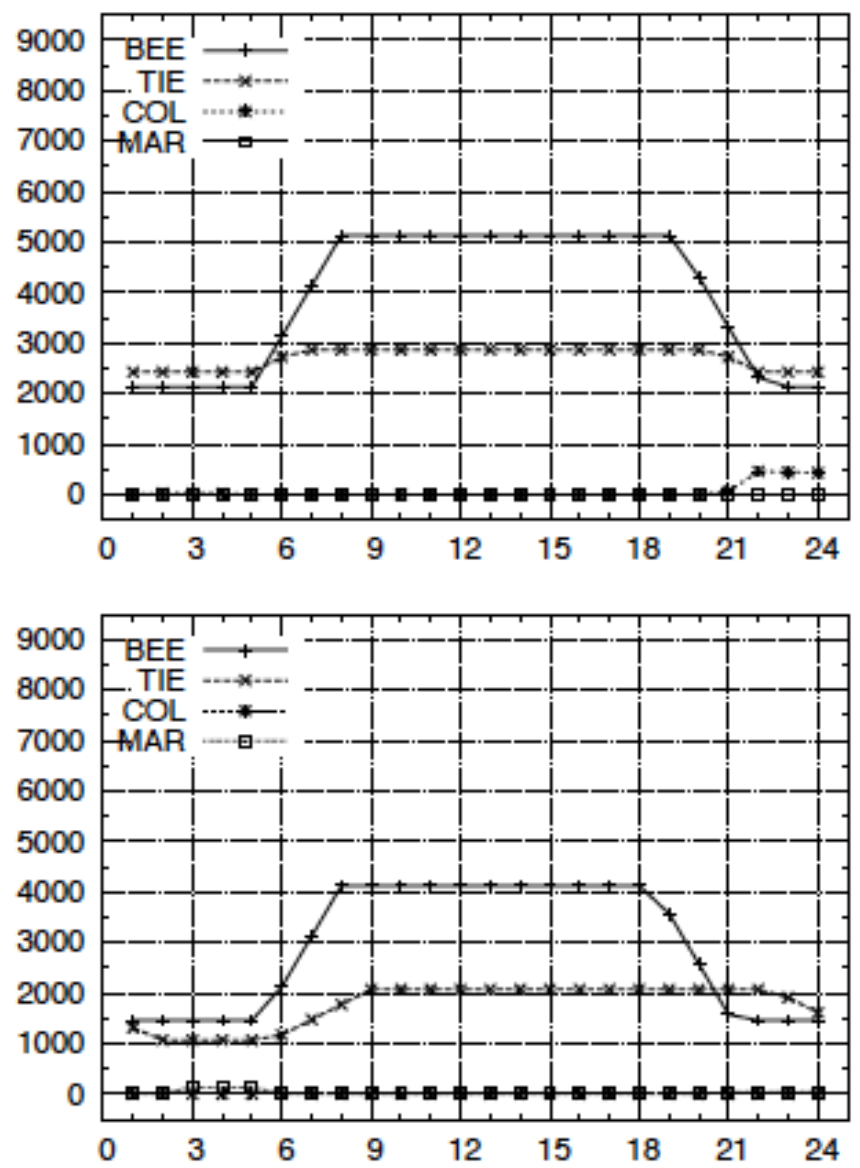

For the network of Berliner Wasserbetriebe, the maximal length of a "short" pipe has empirically been set to $500 \mathrm{~m}$ after several experiments; this value represents the best compromise of model accuracy and computation time. The reduced main network then has 413 nodes and 608 links. The threshold length may be gradually decreased in the future with increasing computing power.

\section{RESULTS}

We consider the municipal drinking water network of Berliner Wasserbetriebe, which has nine waterworks and eight additional pumping stations, five of which are equipped with tanks. The total length of all pipes is $7800 \mathrm{~km}$. There are 256000 household connections, serving a yearly consumption demand of over 200 million $\mathrm{m}^{3}$ with daily demands ranging between roughly half a million and one million $\mathrm{m}^{3}$.

In the waterworks, raw water is extracted via groundwater wells from reservoirs. After treatment, the pure water is stored in tanks and then pumped into the pressurized distribution network. Control actions to be planned include raw water pumping, pure water pumping, filling and emptying of the tanks, and setting of the control valves.

In order to investigate how optimal solutions change with the operating conditions, we consider four scenarios with different combinations of
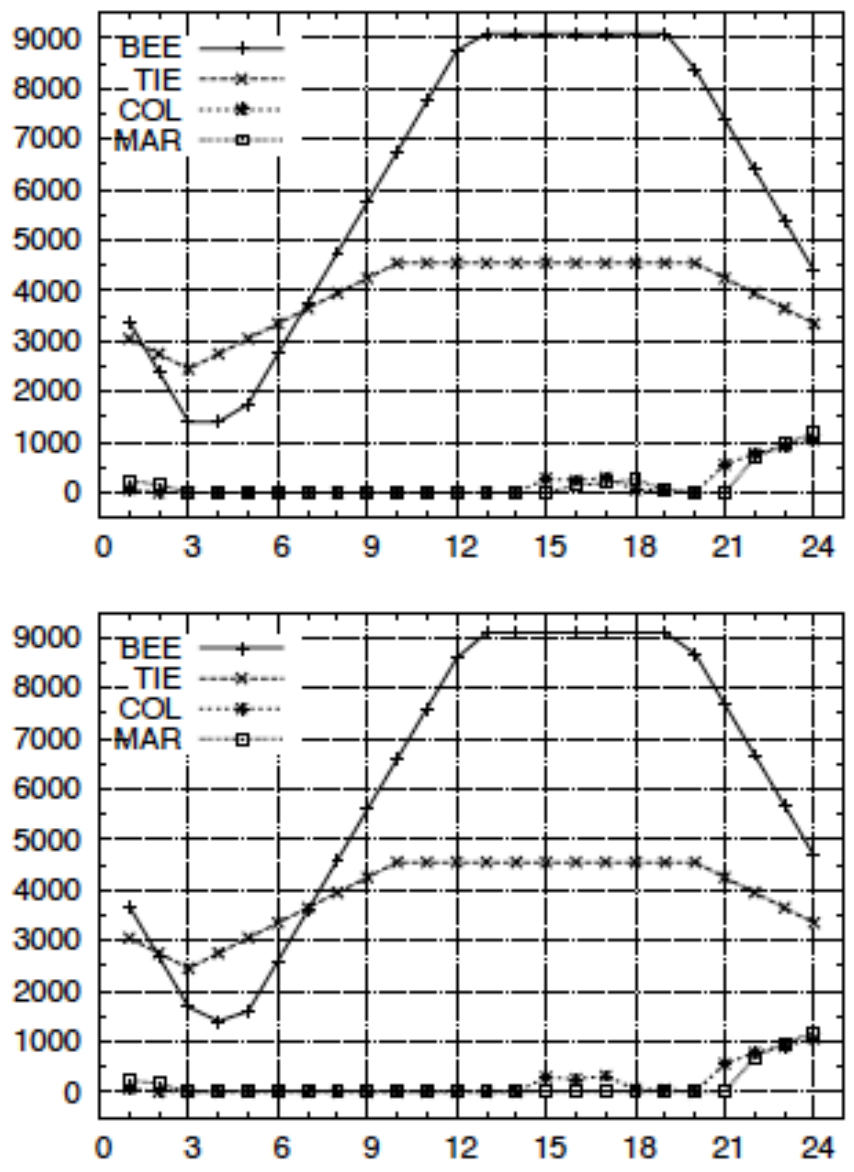

Fig. (7). Optimal raw water production at BEE and TIE, and tank inflows at COL and MAR ( $\mathrm{m}^{3} / \mathrm{h}$ ). Scenarios 1 (top left), 2 (top right), 3 (bottom left), and 4 (bottom right). 
- the demand: normal and high;

- electricity prices: constant and variable;

- groundwater extraction fees: current and previous.

The normal daily demand is $585000 \mathrm{~m}^{3}$, the fictitious high demand is one million $\mathrm{m}^{3}$.

Electricity prices differ between the providers in Berlin and in the federal state of Brandenburg where the waterworks Stolpe is located. In the scenario with variable electricity prices, a reduction by about $13 \%$ has been applied at the waterworks Stolpe during nighttime (18:00-08:00).

The groundwater extraction fees (GEG, Grundwasserentnahmeentgelt in German) also differ between the waterworks of Berlin and Brandenburg. They are about six times higher in Berlin compared to the fees in the federal state of Brandenburg. Within Berlin, the current groundwater extraction fees are identical all over the city, whereas previous fees have been reduced at the waterworks Spandau and Tegel.

In the following, every figure compares for some quantity of interest the time histories of the following four scenarios:

fixed electricity price, current GEG, normal demand (top left, reference);

(2) fixed electricity price, current GEG, high demand (top right);
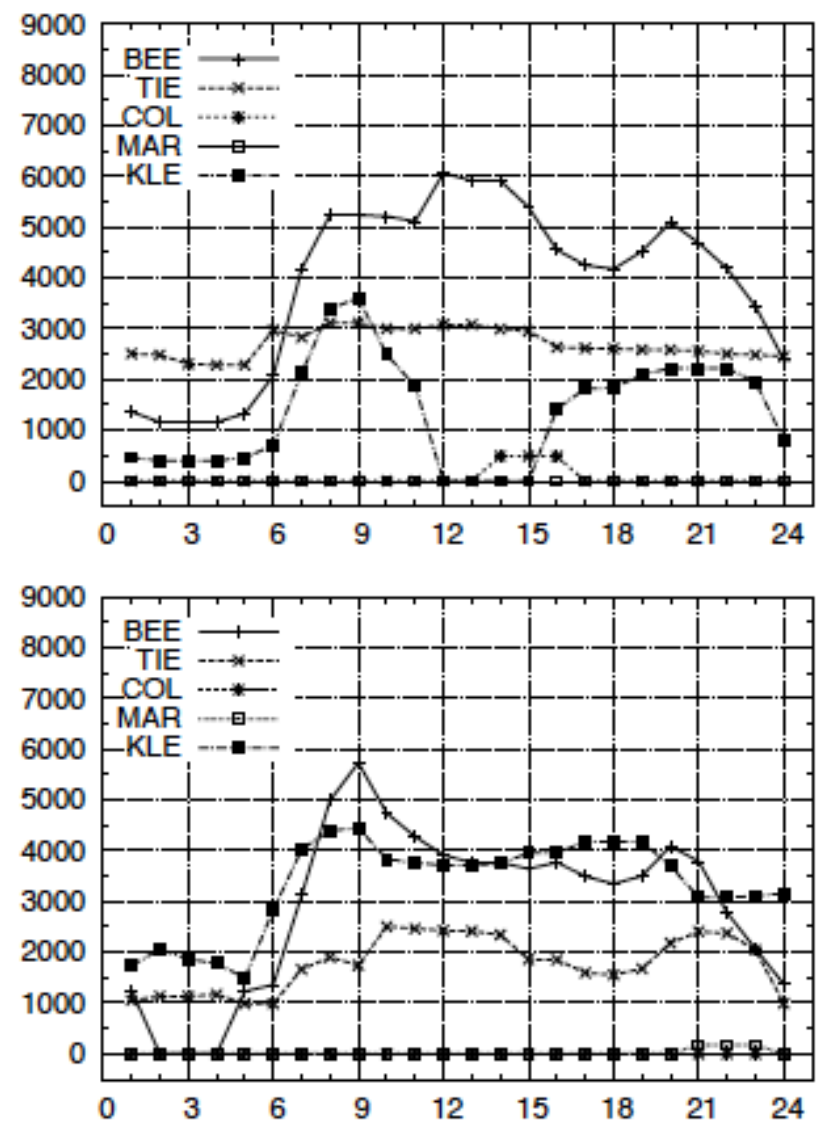

fixed electricity price, previous GEG, normal demand (bottom left);

variable electricity price, current GEG, high demand (bottom right).

The behavior of the entire network is much too complex to visualize; we therefore focus on a selected area in the southern uptown. This area is mainly served by the two waterworks Beelitzhof (BEE) and Tiefwerder (TIE), and it includes three pumping stations: Columbiadamm and Marienfelde (COL and MAR, with tanks), and Kleistpark (KLE, without tank). Note that the GEG differences (at Spandau and Tegel) and the nighttime reduction of the electricity price (at Stolpe) occur far from the area of interest; nevertheless we will see effects on the optimal operation schedules.

Fig. (7) displays the raw water production at waterworks $\mathrm{BEE}$ and TIE, and the tank inflows at pumping stations COL and MAR. We observe that the raw water production is quite steady, as desired. Production is low during nighttime and high during daytime at almost constant levels. The slopes in between are also constant, showing that the gradient constraint (8) is binding. In scenarios 1 and 3 (normal demand) we have brief transitions between long periods with constant levels, and in scenarios 2 and 4 (high demand) we have a long nighttime transition and a brief constant daytime period. The two waterworks are always active in either case. In the case of normal demand, only one pumping station

Fig. (8). Optimal discharge flows into the southern uptown at BEE, TIE, COL, MAR, and KLE ( $\mathrm{m}^{3} / \mathrm{h}$ ). Scenarios 1 (top left), 2 (top right), 3 (bottom left), and 4 (bottom right).
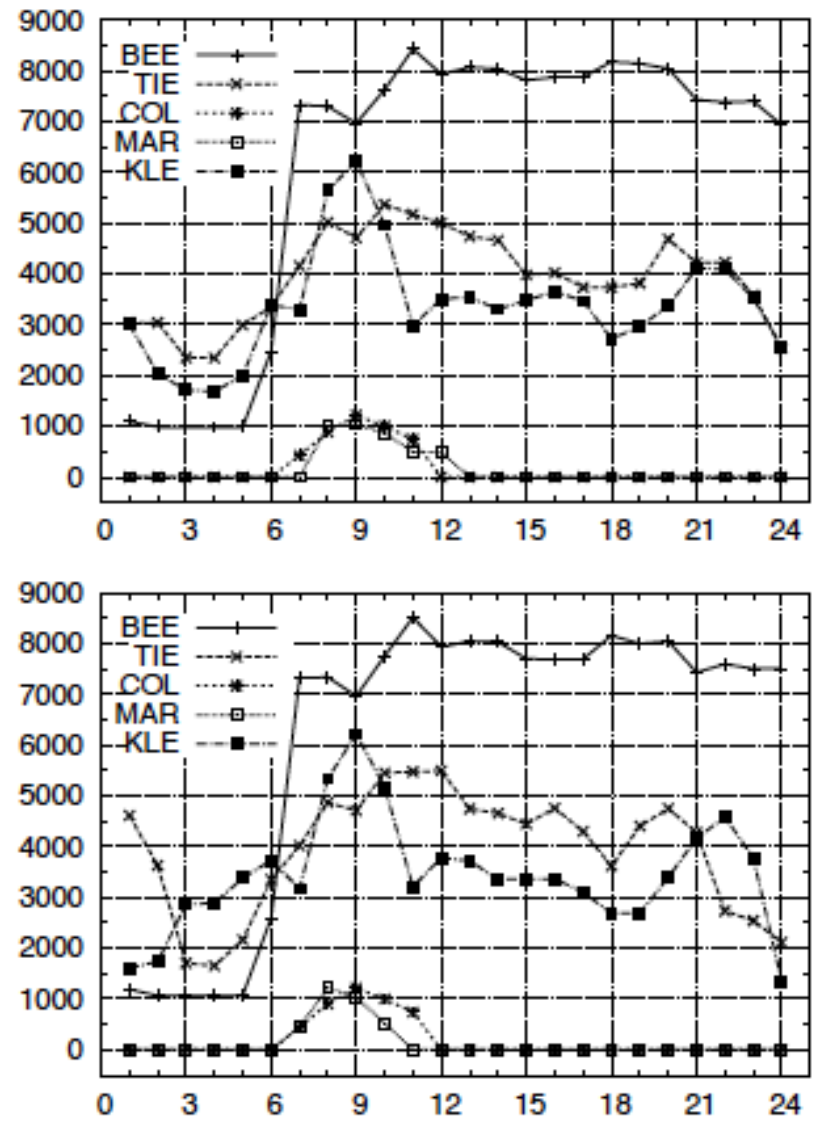

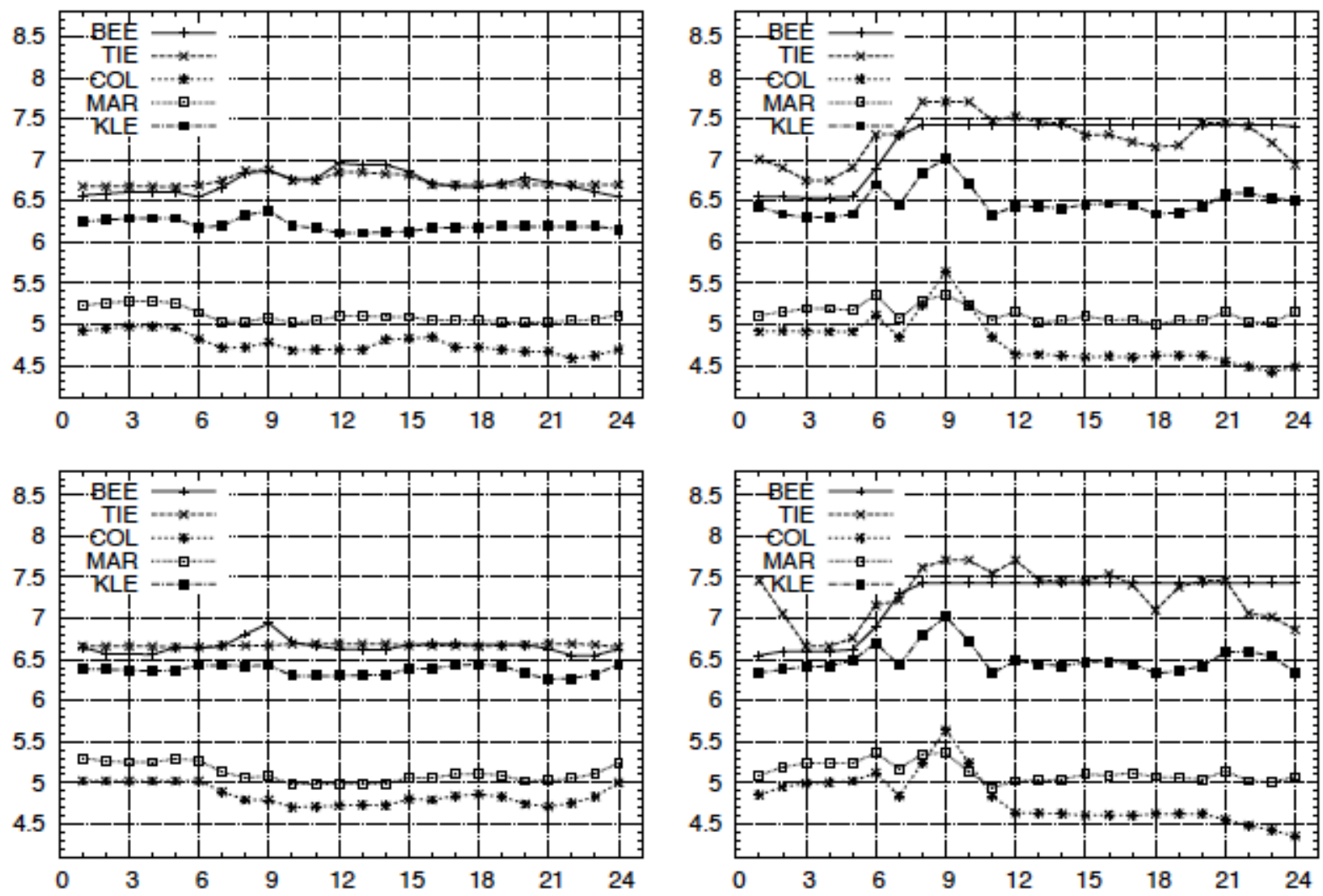

Fig. (9). Optimal outlet pressures into the southern uptown at BEE, TIE, COL, MAR, and KLE (bar). Scenarios 1 (top left), 2 (top right), 3 (bottom left), and 4 (bottom right).

(COL) fills its tank during a brief period (either before midnight or in the early morning, depending on the GEG), whereas heavier nightly tank inflow and an additional lateafternoon inflow occur at both COL and MAR in the case of high demand. If the GEG is reduced, both BEE and TIE produce significantly less water than in the reference case. The reduction of the nighttime electricity price at the distant waterworks Stolpe has no visible effect here.

Fig. (8) displays the outlet flow rates to the southern uptown at waterworks BEE and TIE, and at pumping stations COL, MAR, and KLE. In the reference case (normal demand), the outflow at TIE varies only slightly whereas BEE roughly follows the demand profile and KLE is under heavy load during the morning and evening peaks. Pumping station COL contributes a small share between the peak times. In scenario 2 (high demand) the behavior is totally different. Both BEE and TIE are under heavy load during daytime and still active at nighttime, while both COL and MAR feed the network only during the morning peak. Pumping station KLE works continuously during day and night, supplying a substantial share of water from a neighboring pressure zone where plants with high capacity and high efficiency are located. This effect is even more pronounced with reduced GEG at Spandau and Tegel (scenario 3), where KLE becomes the main source in compensating for the reduced production at BEE and TIE. Variable electricity costs result in lower nighttime supply from KLE and increased supply from TIE.
Fig. (9). displays the outlet pressures at waterworks BEE and TIE, and at pumping stations COL, MAR, KLE. In the case of normal demand we observe only slight pressure variations, as desired. Note that pumping stations COL and MAR reach their maximal pressures during nighttime, although they are not pumping. The reason is that consumption is low, hence there is very little pressure loss from the waterworks outlets to the customers. If the demand is high, there are substantial variations, especially before and during the morning peak, when the pressures reach their maximal values. A reduction of the GEG or the electricity price does not result in significant differences, except for higher nighttime pressure at TIE and lower pressure at KLE in scenario 4 , corresponding to altered pump operation.

Fig. (10) displays the tank filling levels at waterworks BEE and TIE, and at pumping stations COL and MAR. In the case of normal demand, the filling level at TIE is almost constant, and the tank is deflated very slightly during daytime. The tank at BEE is filled during peak times and deflated in between. In the reference case, the tank at COL is full most of the time and is deflated during the evening peak, while the filling level at MAR remains constant. With reduced GEG (scenario 3) the level at COL remains constant while the tank at MAR shows an insignificant deflation during nighttime. The slight variations are partly caused by the constant electricity prices. Another reason is that the potential energy of the water is higher when the tanks are full, which reduces the power consumption of the outlet 

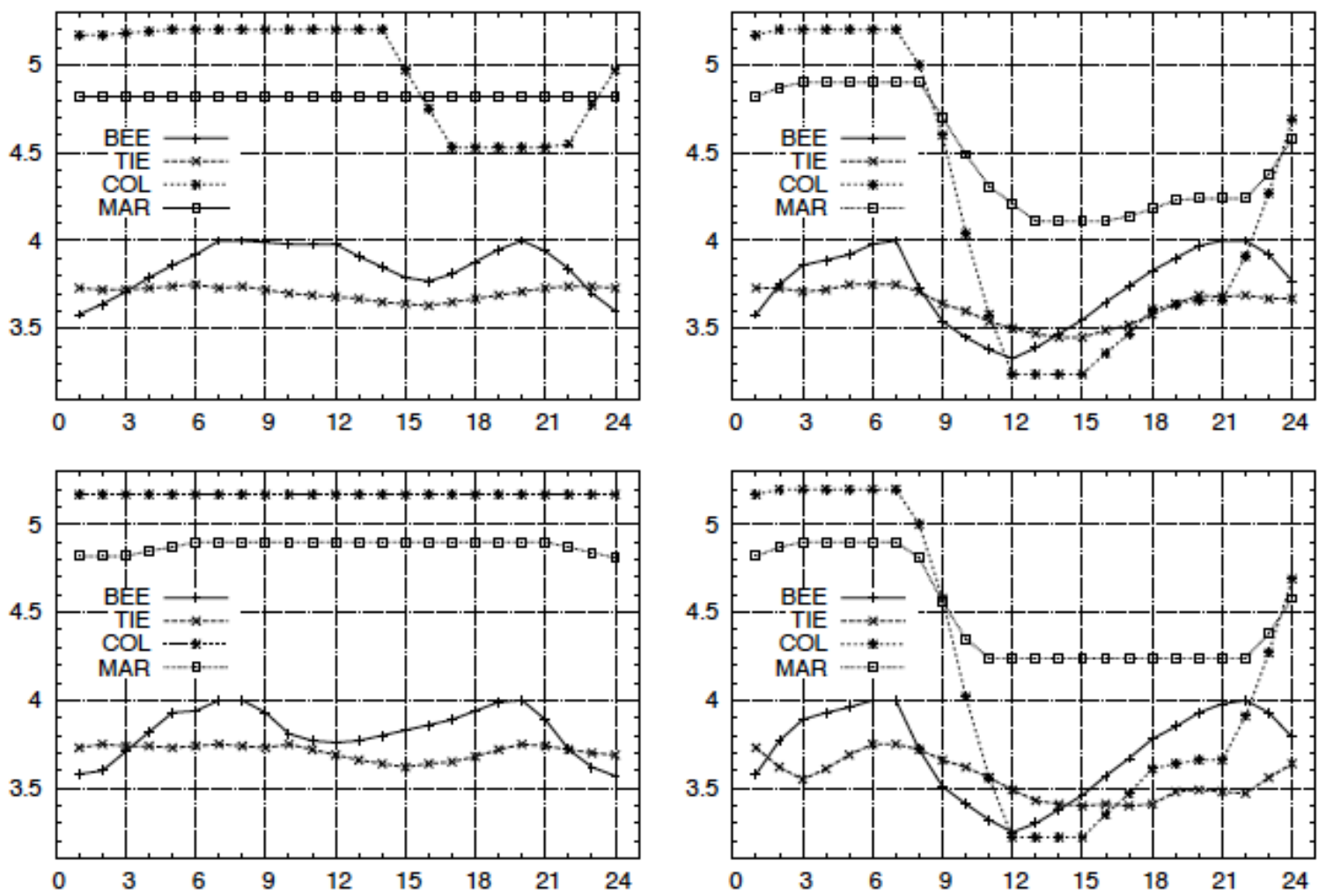

Fig. (10). Optimal tank filling levels at BEE, TIE, COL, MAR (m). Scenarios 1 (top left), 2 (top right), 3 (bottom left), and 4 (bottom right).

pumps. In the case of high demand, the tanks at BEE and TIE are operated as in scenario 1 but with somewhat greater deflation, while the tanks at COL and MAR are both substantially deflated during daytime. This holds irrespective of the reduced nighttime electricity price which, however, causes permanently lower filling levels at TIE.

\section{SUMMARY}

We have presented a method for network-wide operative planning in pressurized water distribution networks that is practically applicable to large networks and under a wide range of operating conditions. An optimization module implementing our approach is integrated into the operational control system at Berliner Wasserbetriebe, where it is used for the daily planning. Such an integration is emphasized in [8] as the "hook" that interests the city water managers in trusting and, ultimately, using the system. Notwithstanding this correct assessment, carefully dovetailed optimization models and numerical methods are essential for obtaining meaningful results, given the enormous complexity of the planning problem. Apart from sub-model approximations, convergence acceleration techniques, and the like, our approach features a network reduction strategy whose tradeoff between accuracy and numerical effort can be adjusted via a scalar parameter. It also features smooth minimum up and down time constraints which, in combination with pump aggregation, enable us to handle pump switching without introducing integral decision variables. Individual pump schedules are obtained in a postprocessing step by solving separate mixed-integer NLP models (MINLP) locally at each outlet, with flows and pressures given by the network-wide NLP solution. The degree of detail for optimization in Berlin is mainly limited by what can be achieved in reasonable response time (up to 30 minutes) on affordable hardware (a PC workstation). From the modeling side, direct extensions to network-wide mixed-integer optimization as well as detailed component models are already available [41]. This allows for more accurate optimization as soon as faster hardware or improved algorithms become available. The use of the current NLP model is likely to result in further gains in efficiency by the development of custom sparse solvers based on similar techniques as in $[35,54]$; in such a way, the rich sparse structure induced by the network model and time discretization can be exploited.

\section{REFERENCES}

[1] Coulbeck B, Brdys M, Orr CH, Rance JP. A hierarchical approach to optimized control of water distribution systems. I: Decomposition. Optim Control Appl Methods 1988; 9(1): 51-61.

[2] Coulbeck B, Brdys M, Orr CH, Rance JP. A hierarchical approach to optimized control of water distribution systems. II: lower-level algorithm. Optim Control Appl Methods 1988; 9(2): 109-26.

[3] Diba A, Louie PWF, Yeh WWG. Planned operation of large-scale water distribution system. J Water Resour Plan Manage 1995; (121): 260-9.

[4] Ernst AT. Continuous-time quadratic cost flow problems with applications to water distribution networks. J Aust Math Soc, Ser B 1996; 37(4): 530-48.

[5] Klempous R, Kotowski J, Nikodem J, Ulasiewicz J. Optimization algorithms of operative control in water distribution systems. J Comput Appl Math 1997; 84(1): 81-99.

[6] Papageorgiou M. Optimal control of generalized flow networks. In: system modelling and optimization, Proceedings $11^{\text {th }}$ IFIP Conference, Copenhagen 1983. Lecture Notes Control Information Science Berlin 1984; vol. 59: pp. 373-82. 
[7] Sun YH, Yeh WWG, Hsu NS, Louie PWF. Generalized network algorithm for water-supply-system optimization. J Water Resour Plan Manage 1995; (121): 392-8.

[8] Wilson RL, Reely BT, Cox M. The water resource management system (WREMS) linking data management and operational optimization. Ann Oper Res 1997; 72: 105-24.

[9] Can EK, Houck MH. Real-time reservoir operations by goal programming. J Water Resour Plan Manage 1984; (110): 297-309.

[10] Carpentier P, Cohen G. Applied mathematics in water supply networks management. Automatica 1993; (29): 1215-50.

[11] Cembrowicz RG. Steuerungsoptimierung eines Wasserversorgungssystems. GWF Wasser/Abwasser 1990; 131(10): 550-62.

[12] Murray DM, Yakowitz SJ. Constrained differential dynamic programming and its application to multireservoir control. Water Resour Res 1979; 15: 223-35.

[13] Orr CH, Parker MA, Tennant ST. Implementation of on-line control scheme for city water system. J Water Resour Plan Manage 1990; (116): 708-26.

[14] Zessler U, Shamir U. Optimal operation of water distribution systems. J Water Resour Plan Manage 1989; (115): 737-51.

[15] Boulos PF, Wu Z, Orr CH, Moore M, Hsiung P, Thomas D. Optimal pump operation of water distribuion systems using genetic algorithm, $\mathrm{H}_{2} \mathrm{ONET}$ - Users Guide. MW Software INC 2000

[16] Cembrano G, Wells G, Quevedo J, Perez R, Argelaguet R. Optimal control of a water distribution network in a supervisory control system. Control Eng Pract 2000; (8): 1177-88.

[17] Cohen D, Shamir U, Sinai G. Optimal operation of multi-quality water supply systems - II: The Q-H model. Eng Optim 2000; 32: 687-719.

[18] Guhl F. Gestion optimale des réseaux d'eau potable [dissertation]. L’Université Louis Pasteur 1999.

[19] Sakarya ABA, Mays LW. Optimal operation of water distribution pumps considering water quality. J Water Resour Plan Manage 2000; 126: 210-20.

[20] Rossman LA. EPANET Users Guide. Cincinnati 1994.

[21] Bragalli C, D'Ambrosio C, Lee J, Lodi A, Toth P. An MINLP solution method for a water network problem. IBM Res Div 2006; RC23893 (W0602-210).

[22] Hansen CT, Madsen K, Nielsen HB. Optmization of pipe networks. Math Program, Ser B 1991; 52: 45-58.

[23] Sherali HD, Subramanian S, Loganathan GV. Effective relaxations and partitioning schemes for solving water distribution network design problems to global optimality. J Glob Optim 2001; 19(1): $1-26$.

[24] Young B. Analysis and optimisation of looped water distribution networks. J Aust Math Soc, Ser B 2000; 41(4): 508-26.

[25 ] Mijaoka S, Funabashi M. Optimal control of water distribution systems by network flow theory. IEEE Trans Automat Contr 1984; 29: 303-11.

[26] Reinisch K, Thümmler C, Hopfgarten S. Hierarchical on-line control algorithm for repetitive optimization with predicted environment and its application to water management problems. Syst Anal, Model Simul 1984; 1:263-80.

[27] Andersen JH, Powell RS, Marsh JF. Constrained state estimation with applications in water distribution network monitoring. Int J Syst Sci 2001; 32(6): 807-16.

[28] Laird CD, Biegler LT, van Bloemen Waanders BG, Bartlett RA. Time dependent contamination source determination for water networks using large scale optimization. J Water Resour Plan Manage 2005; 131(2): 125-34.

[29] de Wolf D, Smeers Y. The gas transmission problem solved by an extension of the simplex algorithm. Manage Sci 2000; 46(11): 1454-65.

[30] Ehrhardt K, Steinbach MC. Nonlinear optimization in gas networks. In: Bock HG, Kostina E, Phu HX, Rannacher R, Eds. Modeling, Simulation and Optimization of Complex Processes. Berlin: Springer 2005; pp. 139-48.
[31] Gugat M. Boundary controllability between sub-and supercritical flow. SIAM J Control Optim 2003; 42: 1056-70.

[32] Gugat M, Leugering G, Schittkowski K, Schmidt EJPG. Modelling, Stabilization, and control of flow in networks of open channels. In: Grötschel M, Krumke SO, Rambau J, Eds. Online optimization of large scale systems. Berlin: Springer 2001; pp. 251-70.

[33] Leugering G, Schmidt EJPG. On the modelling and stabilization of flows in networks of open canals. SIAM J Control Optim 2002; 41(1): 164-80.

[34] Ostapenko VV, Pavlygin AI. Dynamic network flows for generalized Kirchhoff law. Cybern Syst Anal 1996; 32(3): 309-97.

[35] Steinbach MC. On PDE solution in transient optimization of gas networks. J Comput Appl Math 2007; 203(2): 345-61.

[36] Burgschweiger J. Grundlagenermittlung zum Modul Optimierung innerhalb des LSW-Managementsystems. Internal Report, Berliner Wasserbetriebe 2001.

[37] Burgschweiger J. Optimierung der verteilten Wasserförderung in großen Rohrnetzen. Internal Report, Berliner Wasserbetriebe 2002.

[38] GAMS - A Users Guide. Redwood City: Scientific Press 1988.

[39] Gnädig B, Steinbach MC. Betriebsoptimierung der Berliner Trinkwasserversorgung. Study for ABB Utilities $\mathrm{GmbH}$, Mannheim. Zuse Institute Berlin 2003.

[40] Gnädig B, Steinbach MC. Betriebsoptimierung der Berliner Trinkwasserversorgung mit Gesamtnetzmodell. Study for ABB Utilities GmbH, Mannheim. Zuse Institute Berlin 2004.

[41] Burgschweiger J, Gnädig B, Steinbach MC. Optimization models for operative planning in drinking water networks. Optim Eng 2009; 10(1): 43-73. Published online 2008.

[42] Byrd RH, Gould NIM, Nocedal J, Waltz RA. An algorithm for nonlinear optimization using linear programming and equality constrained subproblems. Math Program Ser B 2004; 100(1): 2748.

[43] Chin CM, Fletcher R. On the global convergence of an SLP-filter algorithm that takes EQP steps. Math Program 2003; 96(1): 16177.

[44] Fletcher R, de la Maza ES. Nonlinear programming and nonsmooth optimization by successive Linear programming. Math Program 1989; 43(3): 235-56.

[45] Byrd RH, Nocedal J, Waltz RA. Feasible interior methods using slacks for nonlinear optimization. Comput Optim Appl 2003; 26(1): 35-61

[46] Hackländer P. Integrierte Betriebsplanung von Gasversorgungssystemen. Verlag Mainz, Wissenschaftsverlag, Aachen 2002.

[47] Martin A, Möller M. Cutting Planes for the optimization of gas networks. In: Bock HG, Kostina E, Phu HX, Rannacher R, Eds. Modeling, Simulation and optimization of complex processes. Berlin: Springer 2005; pp. 307-29.

[48] Möller M. Mixed integer models for the optimisation of gas networks in the stationary case [dissertation]. Technische Universität Darmstadt 2004.

[49] Benson HY, Shanno DF, Vanderbei RJ. Interior-Point methods for nonconvex nonlinear programming: complementarity constraints. Princeton University 2002; ORFE 02-02.

[50] Fletcher R, Leyffer S. Solving mathematical programs with complementary constraints as nonlinear programs. Optim Methods Softw 2004; 19(1): 15-40.

[51] Raghunathan AU, Biegler LT. Interior point methods for mathematical programs with complementarity constraits (MPCCs)USA. Carnegie Mellon University 2003.

[52] Scholtes S. Convergence properties of a regularization scheme for mathematical programs with complementarity constraints. SIAM J Optim 2001; 11(4): 918-36.

[53] Stein O, Oldenburg J, Marquardt W. Continuous reformulations of discrete-continuous optimization problems. Comput Chem Eng 2004; 28(10): 1951-66.

[54] Ehrhardt K, Steinbach MC. KKT Systems in operative planning for gas distribution networks. Proc Appl Math Mech 2004; 4(1): 606-7.

Received: September 15, 2008

Revised: November 21, 2008

Accepted: January 11, 2009

(C) Burgschweiger et al.; Licensee Bentham Open.

This is an open access article licensed under the terms of the Creative Commons Attribution Non-Commercial License (http://creativecommons.org/licenses/by$\mathrm{nc} / 3.0 /$ ), which permits unrestricted, non-commercial use, distribution and reproduction in any medium, provided the work is properly cited. 